\title{
The Ability of Financial Ratios to Predict the Index of Banking Sector in Amman Stock Exchange: An empirical study
}

Ahmad Abdallah Ahmed Alswalmeh*

Researcher, Department of Accounting,

Faculty of Economics \& Administrative Sciences,

Yarmouk University, Irbid-Jordan.

Email: aalswalmeh89@gmil.com

\section{Mahmoud Hasan Salem Qaqish}

Full Professor, Department of Accounting,

Faculty of Economics \& Administrative Sciences,

Yarmouk University, Irbid-Jordan.

Email: mqaqish@yu.edu.jo

\section{Received November, 2020; Accepted Januaray, 2021}

\begin{abstract}
The main objective of this study is to test the predictive power of the financial ratios (ownership ratio, liquidity ratio, debt ratio, stock turnover ratio, return on equity ratio, return on total assets ratio, and market to book ratio) on the performance of the banking sector in Amman Stock Exchange (ASE). The analysis relies on yearly data for the period 2000-2014. The sample consists of fourteen banks listed on Amman Stock Exchange. Using the ordinary least square method (OLS), we regress the seven selected variables against the index of the banking sector. The findings show that the financial ratios can predict the behavior of the index in the banking sector. There is a statistically significant positive relationship between the liquidity ratio, debt ratio, stock turnover ratio, return on total assets ratio, market to book ratio with the banking index. While the return on equity is negatively associated with the banking index. There is no statistically significant relationship between the ownership ratio and the index in the Amman Stock Exchange.
\end{abstract}

Keywords: Financial Ratios; Banking Sector Index; Jordanian Banks; ASE

Type: Research paper

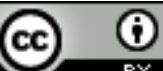

EY This work is licensed under a Creative Commons Attribution 4.0 International License.

DOI: $10.51325 /$ ijbeg.v4i1.55

$$
\begin{aligned}
& \text { قُرة النسب المالية على التبؤ بمؤشر القطاع المصرفي في بورصة عمّان: دراسة تطبيقية } \\
& \text { مُلخّص الدراسة: } \\
& \text { تهدف الدراسة إلى إختبار قدرة نسبة الملكية، والسيولة، ومعدل المديونية، ومعدل دوران السهم، والعائد على حقوق المساهمين، والعائد على } \\
& \text { مجموع الموجودات، والقيمة السوقية إلى القيمة الدفترية في التتبؤ بمؤشر القطاع المصرفي ببورصة عمّان للفترة ما بين } 2005 \text { و } 2014 . \\
& \text { شملت عينة الدراسة } 14 \text { بنك، وتم الحصول على البيانات من خلال القوائم المالية. استخدمت الدراسة طريقة المربعات الصغرى (OLS) } \\
& \text { لتقدير معادلة الإنحدار وإختبار القدرة التنبؤية للنسب المالية في مؤشر القطاع المصرفي. أظهرت النتائج أن النسب قادرة على التنبؤ } \\
& \text { بالمؤشر، وذلك لوجود أثر إيجابي دال إحصائياً لنسبة السيولة، ومعدل المديونية، ومعدل دوران السهم، والعائد على مجموع الموجودات، } \\
& \text { والقيمة السوقية إلى القيمة الدفترية على مؤشر القطاع المصرفي في بورصة إئة عمان. كما بينت الدراسة أن هناك أثر سلبي دال إحصائيا }
\end{aligned}
$$

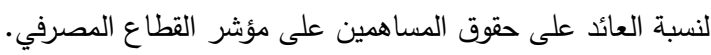

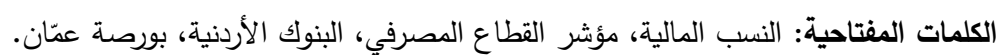


أدى تطوّر النشاط الإقتصادي في الدول وزيادة أعداد المنشآت الإقتصادية إلى قيام مؤسسات تقوم بتجميع المدّخرات وتوظيفها في مختلف القطاعـات، ومن ضمن هذه المؤسسات الأسواق المالية؛ ونتيجة لزيادة أعداد المشاريع والثركات، نشأت الحاجة إلى تكوين أسواق للتداول في أسهح هذه الثركات، حتى أصبح تطويرها أمراً

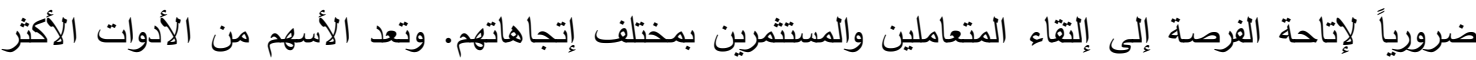

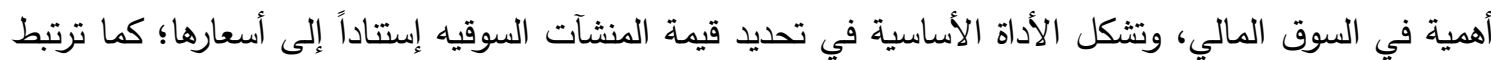

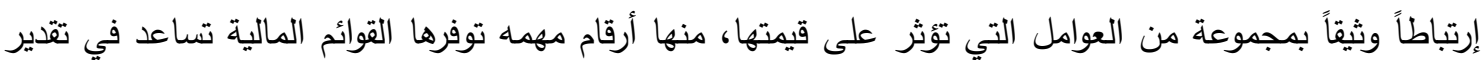

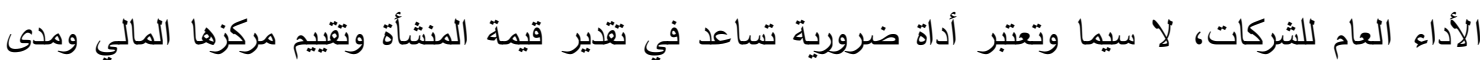
فعالية أنشطتها المختلفة وكفاءتها، كل ذلك جعل دراسة هذه العوامل محط إهتمام الباحثين بصورة مستمرة Merza Radhi and 2012؛ Subramanyam \& Wild, 2009) .(Sarea, 2019; Ali et al., 2018, Alareeni, 2018, 2019) وتوفر تقارير الشركات للمستثرين والدائنين وأطراف أخرى معلومات مهمه في إتخاذ القرارات الرشيدة بشأن إستثماراتهم، وأية قرارات أخرى متعلقة بتلك الإستثمارات، حيث يحتوي التقرير المالي على معلومات تؤثر على سلوك المستثرر، ينعكس فيما بعد على القرار الاستثماري. ويعد حساب النسب من المؤشرات الهامة التي تحدد كفاءة بنود

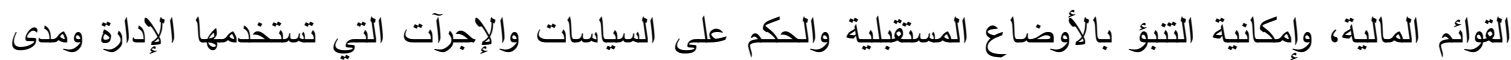

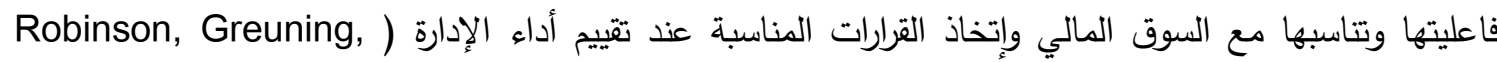

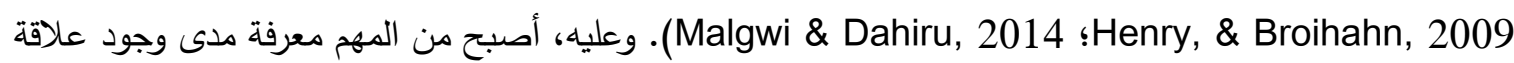
بين النسب المالية والمؤشرات الأخرى وقياس قدرتها على التتبؤ بمؤشر السوق العام أو مؤشرات القطاعات المختلفة، والذي ينعكس فيما بعد على وضع الخطط والسياسات المالية من قِبل الثركات حتى مسارها الصحيح في تحقيق لصوتيق

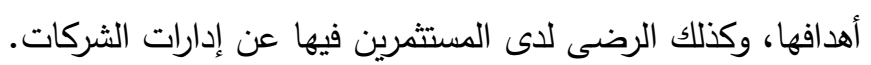

مُشكلة الدراسة:

يُعتبر التحليل المالي باستخدام النسب من التطبيقات المهمة التي تستخدمها الشركات، حتى أصبح ضرورة ملحة لمعرفة العلاقة بينها والمؤشرات المختلفة؛ في حين أن المحللون في شركات الأعمال يواجهون تحديات كبيرة لتحديد

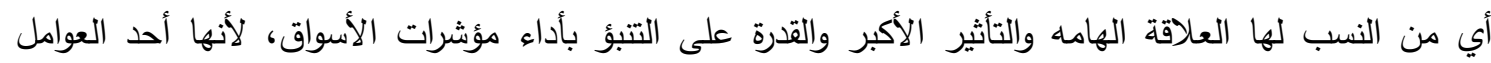

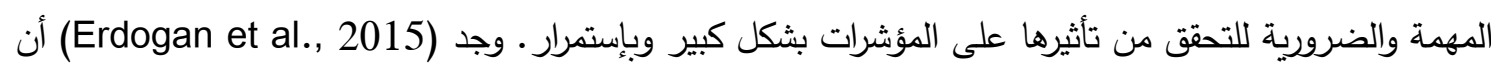

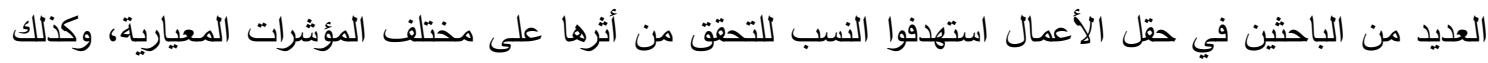

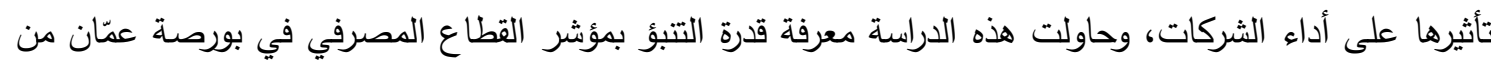

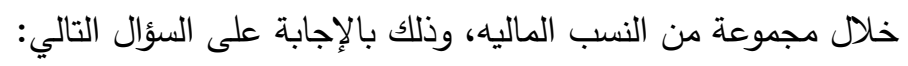
ما هي قدرة نسبة الملكية، والسيولة، ومعدل المديونية، ومعدل دوران السهم، والعائد على حقوق المساهمين،

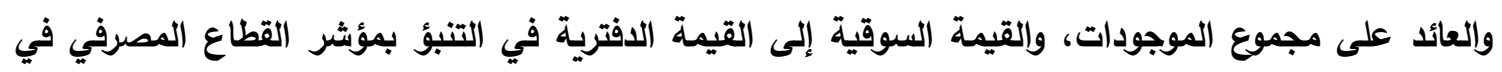
بورصة عمّان أهداف الاراسة

تهدف الدراسة إلى اختبار اثر نسب التحليل المالي ومدى قدرتها على التتبؤ بمؤشر القطاع المصرفي، من خلال قياس أثر 7 نسب على تقلبات مؤشر القطاع المصرفي في بورصة عمان ضمن سلسة زمنية محددة. على وجه الثها

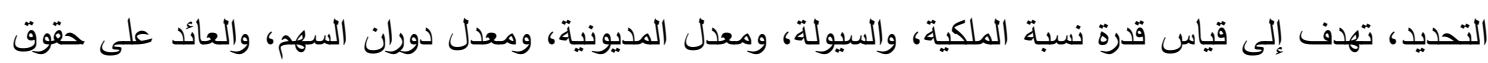


المساهمين، والعائد على مجموع الموجودات، والقيمة السوقية إلى القيمة الدفترية في التتبؤ بمؤشر القطاع المصرفي. أهمية الدراسة تمثلت أهمية هذه الدراسة في معرفة وقياس قدرة النسب المالية للبنوك الأردنية عن طريق نسب التحليل المالي على التتبؤ بمؤشر القطاع المصرفي، والذي بدوره يُتيح الفرصة لبناء توقعات مستقبلية للمؤشر بطريقة علمية فئية مدنهجة

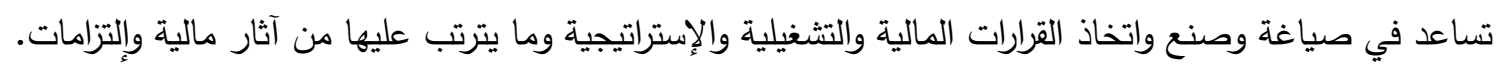

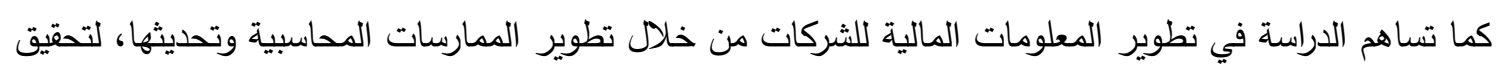
جودة وشفافية المعلومات المنشورة، ما ينعكس بشكل مباشر على الأداء العام للسوق، والذي يؤثر بشكل ايجابي على الإقتصاد بشكل عام. الإطار النظري للاراسة

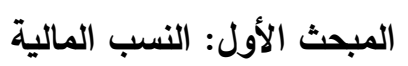
تقيد النسب المالية في قرار الإستثمار، وتقييم جوانب نثاط المشروع في اوقات معينة وكذلك عقد مقارنات تثمل

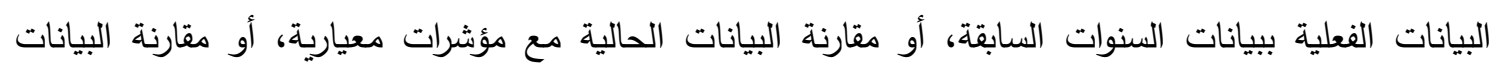

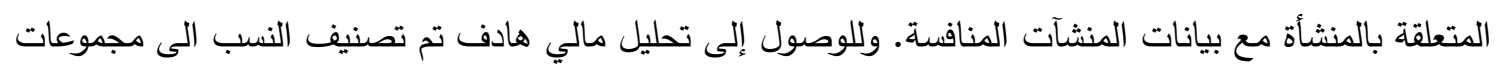

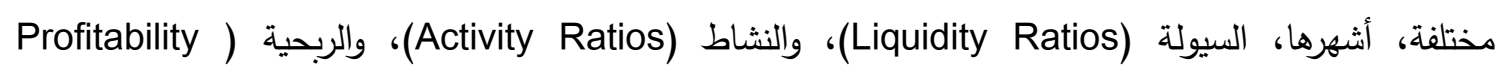
(Ratios)، والمديونية (Debt Ratios)، والسوق (Market Ratios). تحتوي كل مجموعة على نسب مختلفة، تم

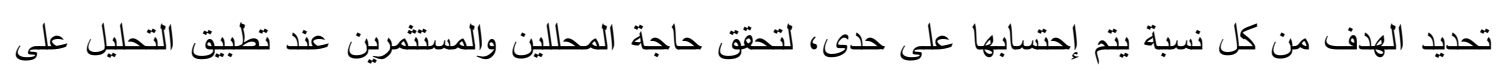

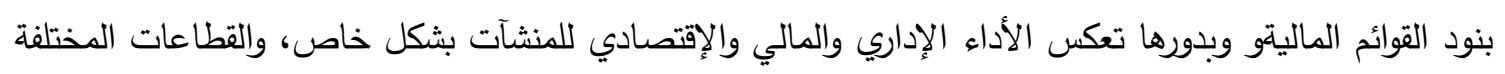

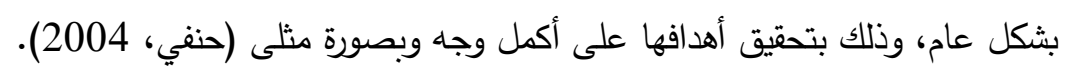

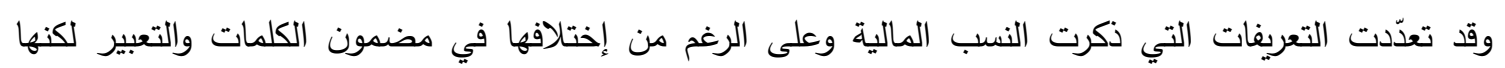

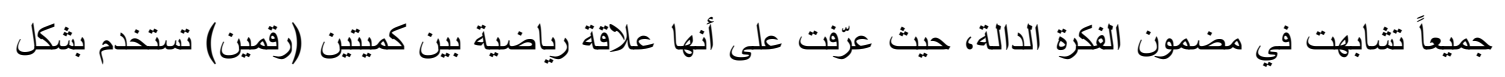

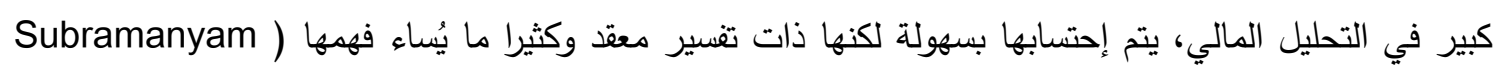
(2004) أنها نسبة رقم معين من أرقام القوائم المالية إلى رقم آخر من أرقام

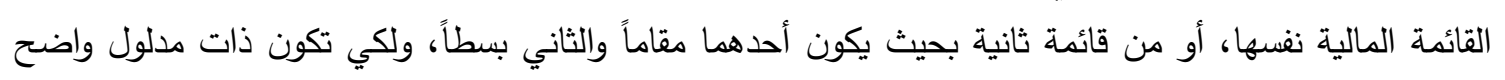

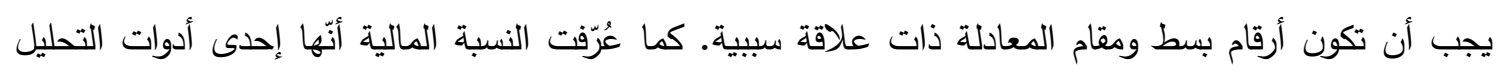
المالي دالة على مجموعة من العلاقات المنطقية بين رقمين، ولكي تعتبر مؤشرات ذات معنى يجب أنس أن تكون

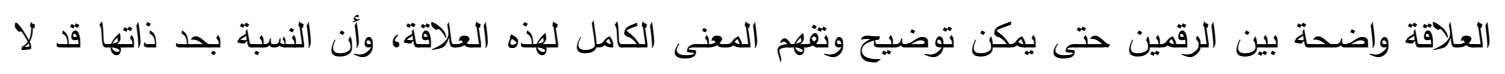

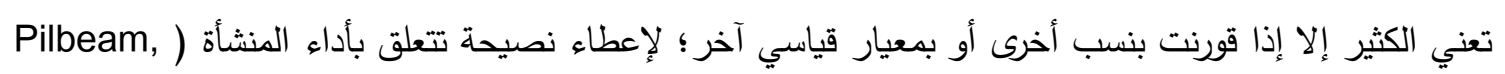

وإعتماداً على ما سبق نُعرف النسب المالية على أنها مؤشرات هامة تستخدم للتحقق من مدى ربحية المنشآت

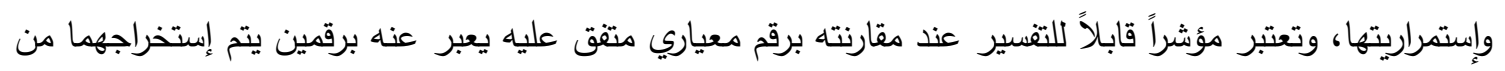

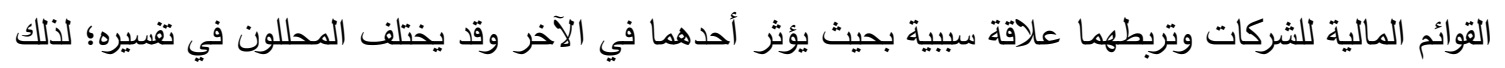
يجب أن يدرك المحللون أهمية هذه النسب ومدى حساسية تفسيرها بصورة صحيحة.

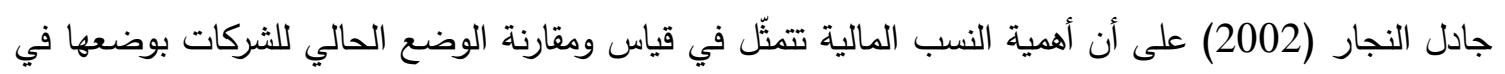
السنوات السابقة عن طريق تحليل وقياس تذبذب أداء المنشأه عبر سنين مختلفة في الماضي، وإكتثاف نقاط 
الضّعف والقوّة في السياسة المالية المتبعة من قبل إدارة الثركات، والكثف عن جودة وصحة القوائم المالية وعن الأخطاء الواردة فيها (إن وجدت) ومدى إمكانية تفاديها مستقبلاً. يوجد العديد من النسب المالية يمكن إستخدامها في تقييم أداء الثركات، ويمكن توظيف كل نسبة من هن هذه النساء لقياس أداء المنشأة من زاوية محددة للوصول إلى أرقام يستطيع المحلل تفسيرها بما يخدم المهتمين، والمستثرين للإطلاع على وضع إستثماراتهم؛ وأبرزها:

أولاً: نسب السيولة (Liquidity Ratios). تعتبر نسب السيولة أدوات لتتييم المركز الإتتماني للمنشأة حيث تقيس مدى قدرتها على أداء إلتزاماتها القصيرة

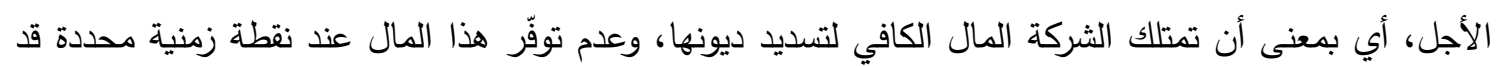
يعرض الثركة إلى مخاطر السيولة (Harrington, 1993). 1) نسبة التداول: تهدف إلى قياس قدرة المنشأة على مواجهة إلتزاماتها المستحقّة في موعدها، وعبر عنها (Bragg, 2007)

"نسبة التداول = الموجودات المتداولة / المطلوبات المتداولة"

وتعتبر مقياساً عامّاً لنسبة السيولة في المنشأة، لأنها تقدم أفضل مؤشر عن مدى تغطية الإلتزامات المتداولة

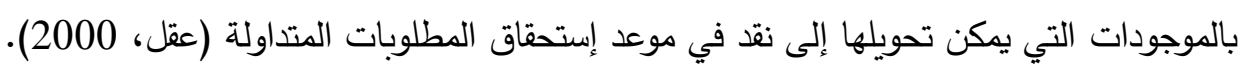
2) نسبة السيولة السريعة: تهاف إلى بيان قدرة المنشأة على سداد إلتزاماتها قصيرة الأجل دون الإعتماد على فئى البضاعة، وعبّر عنها الثنطي وشقر (2004) رياضياً:

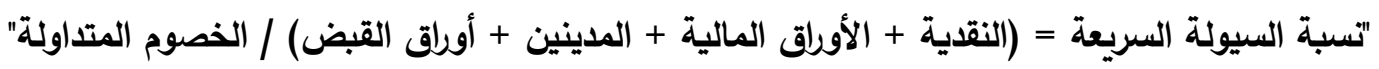

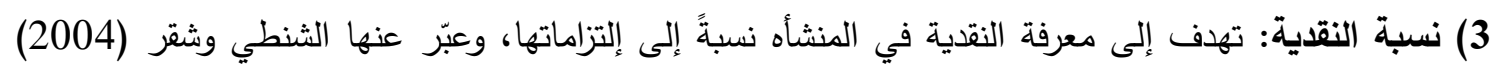
رياضياً:

"نسبة النقدية = الموجودات النقدية وشبه النقدية / المطلوبات المتداولة"

4) صافي رأس المال العامل: تهدف إلى قياس "صافي رأس المال التشغيلي عند نقطة معينة"، وعبّر عنها السعايدة وفريد (2004) رياضياً:

"صافي رأس المال العامل = الموجودات المتداولة - المطلوبات المتداولة"

ثانياً: نسب النشاط (Activity Ratios).

تستخدم نسب النشاط لتقييم مدى نجاح إدارة الثركات في إدارة أصولها، ومدى كفاءتها في إستغلال مواردها

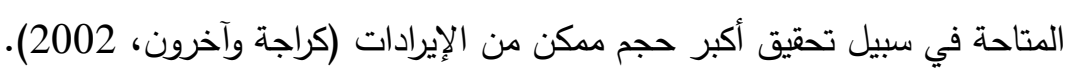
1) معدل دوران مجموع الأصول: تقيس مدى إستغلال مجموع الموجودات في المنشأة لإيجاد المبيعات، وعبّر عنها الدوري وزناد (2003) رياضياً:

"معدل دوران مجموع الأصول = صافي المبيعات / مجموع الأصول"

2) معدل دوران الأصول المتداولة: تقيس مدى استخدام الأصول المتداولة في ايجاد المبيعات، وعبّر عنها المبات الاهول السعايدة وفريد (2004) رياضياً:

"معدل دوران الأصول المتداولة = صافي المبيعات / مجموع الأصول المتداولة"

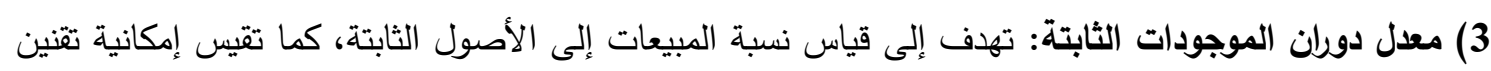

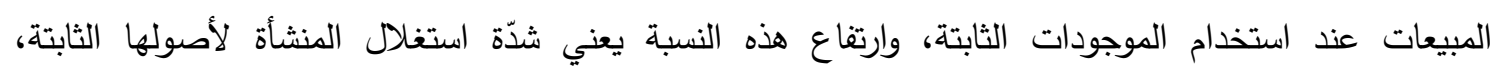
وانخفاضها يعني استثمار زائد في الأصول الثابتة، وعبّر عنها كراجة وآخرون (2002) رياضياً: 
"معدل دوران الأصول الثابتة = صافي المبيعات / مجموع الأصول الثابتة"

ثالثاً: نسب الربحية (Profitability Ratios).

تقيس كفاءة الثركة في تحقيق الأرباح، والسياسات والقرارات الإستثمارية المتخذة من الإدارة، كما تثير هذه النسب

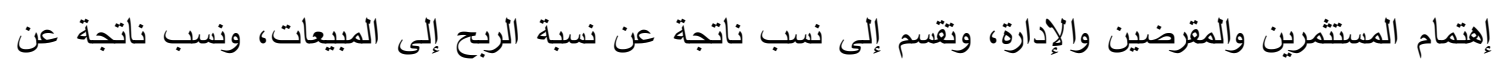
نسبة الربح إلى الإستثمارات (آل شبيب, 2006).

1) نسبة صافي الربح إلى المبيعات: تبيّن إلى أي مدى يمكن أن ينخفض سعر الإنيتّات الوحدة قبل أن تتحمل المنشأة

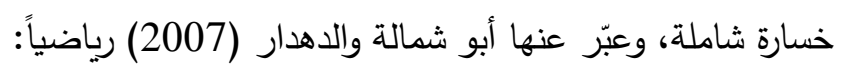
"نسبة الربح إلى المبيعات = صافي الربح / صافي المبيعات"

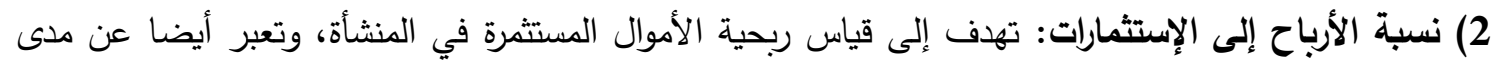
إستخدام المنشأة لمواردها المتاحة، وتتمثل بنسبة العائد على الموجودات، وعبّر عنها النعيمي والتميمي (2008) رياضياً:

"العائد على الموجودات = صافي الربح بعد الضريبة / مجموع الموجودات"

رابعاً: نسب المديونية (Debt Ratios).

تعطي مؤشرات دقيقة حول الوضع المالي للشركات على المدى الطويل من ناحية، وتبين قدرتها على الى المدي

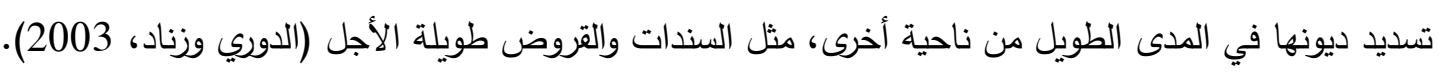

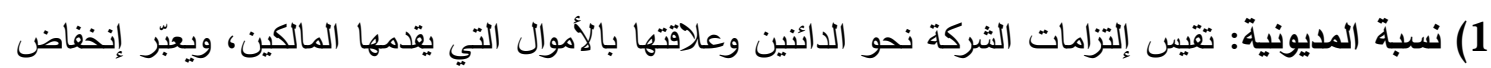

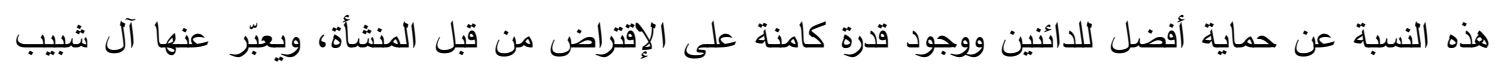
(2006)

"نسبة المديونية = إجمالي الديون (قصيرة وطويلة الأجل) / حقوق الملكية"

2) نسبة التغطية الثاملة: تهدف إلى معرفة قدرة الشركة على دفع الإلتزامات الثابتة من أرباحها، وقد أطلق عليها لإبها نسبة التغطية الثاملة لثمولها في المقام الإلتزامات الموقعّة على الثركة خارج نطاق تكاليف العمليات جميعها، وعبّر عنها الثنطي وشقر (2004) رياضياً:

"تسبة التغطية الثاملة = الاخل النقدي المتاح لمواجهة الإلتزامات الثابتة / الإلتزامات الثابتة"

خامساً: نسب السوق (Market Rates).

تخدم محللي الأسهم أثناء القيام بههامه عند تقييم أداء الثركات، وتخدم المستثمرين الحاليين والمحتملين عند التعامل في السوق المالي بما يتتاسب مع إتجاهات الأسعار السوقية للشركات، ويعتبر إرتفاعها مؤشراً إيجابياً،

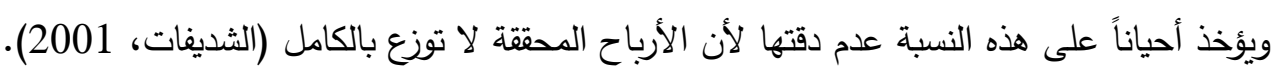

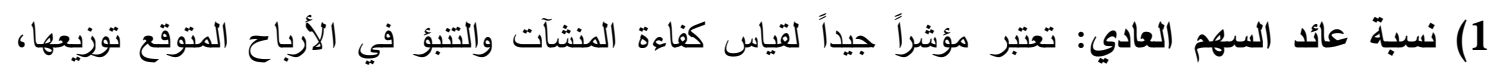

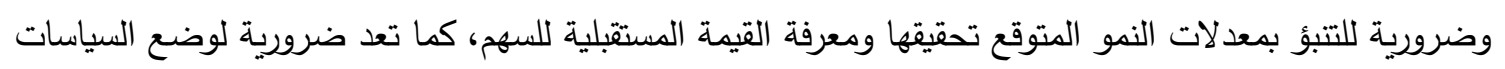
الخاصة بالأرباح، وعبّر عنها مطر (2003) رياضياً:

"عائد السهم العادي = (صافي الربح بعد الضريبة - توزيعات الأسهم الممتازة) / عدد الأسهم العادية"

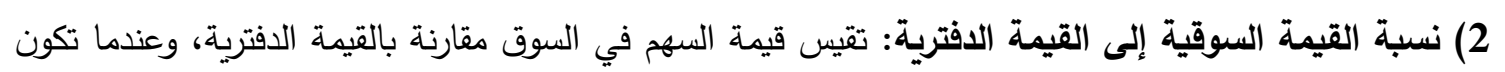

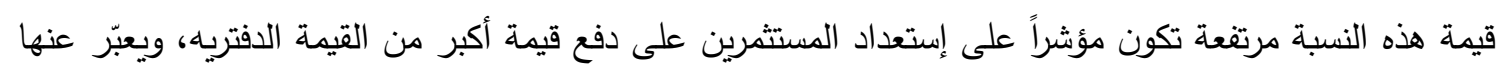
قسم الأبحاث في بورصة عمّان (2011) رياضياً:

"تسبة القيمة السوقية إلى القيمة الدفترية = القيمة السوقية للسهم / القيمة الدفترية للسهر" 
3) نسبة سعر السهم إلى عائده: تقيس توقعات الشركة المستقبلية في السوق، ويعتبر إرتفاعها إيجابياً بالنسبة

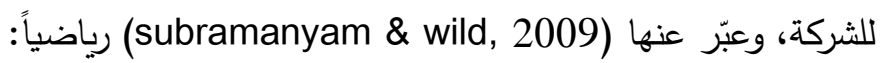
"نسبة سعر السهم إلى عائده = القيمة السوقية للسهم / العائد المحقق على السهم"

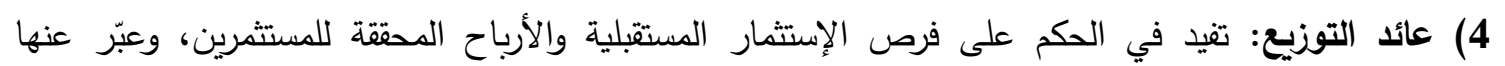
الثنطي وشقر (2004) رياضياً:

"عائد التوزيع = حصة السهم من الأرباح الموزعة / سعر السهم السوقي" (لئي" المبحث الثاني: مؤشر القطاع المصرفي تعدّدت المفاهيم التي ذكرت مؤشر السوق لكنها تشابهت في مضدون التطبيق وطرق القياس، منها أن المؤشر مدلول إحصائي يتم إحتسابه لقياس أداء السوق أو القطاع الذي يحتسب له له (الثلبي، 2000). (2002) مؤشر السوق أنه مجموعة من أسهم عدد من الشركات تمثل عينة تؤخذ حركة أسعارها كإنعكاسات للإتجاهات المستقبلية للأسعار في السوق. وقد عُرّف مؤشر سوق الأوراق المالية أنه أداة تقيس مستوى أسعار

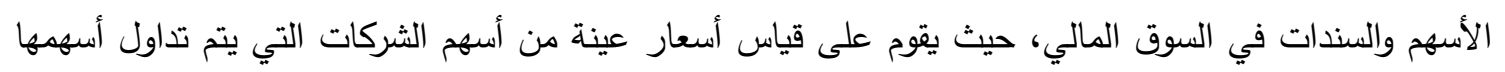
وسنداتها في أسواق رأس المال، ويكون المؤشر العام للسوق مرآة للحالة الإقتصادية العامة للدولة (الزرري، 2001). وإعتماداً على ما ورد، نعرف مؤشر القطاع المصرفي على أنه أداه تقيس اتجاه أسعار أسهم البنوك من خلال تتبع حركة أسعار اسهم البنوك المدرجة في القطاع المصرفي والذي من خلاله يمكن التتبؤ بإتجاهات الأسعار المستقبلية.

وقد فنّد السهلي (2011) جملة من الخصائص لمؤشرات الأسواق المالية، منها أن المؤشر يُعبَّر بعدد من النقاط ويُعتبر قيمة متوسطة تعبّر عن الأوراق المقيدة في السوق، وإذا تم حسابه لعينة معينة من السوق، فإن النتيجة تكون

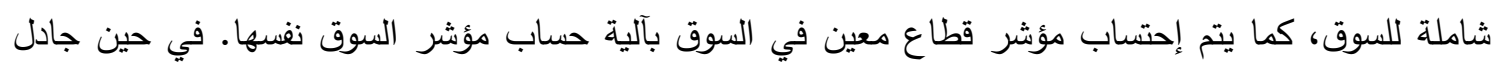

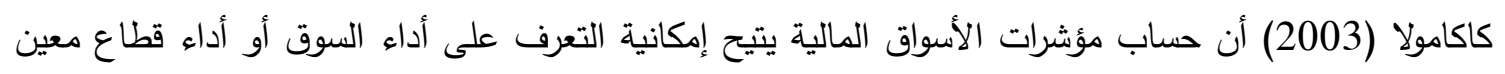

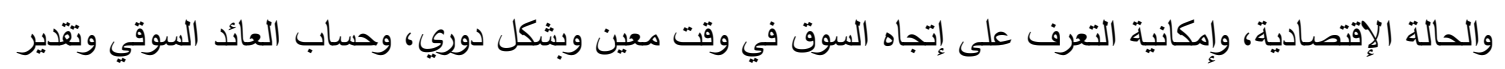

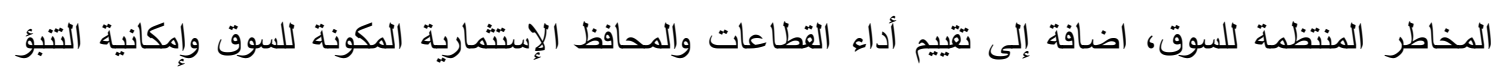
بأدائه ومعرفة إتجاهاته المستقبلية. ويتكون الجهاز المصرفي الأردني من البنك المركزي الأردني و25 بنكاً منها: 13 بنكاً تجارياً محلياً، و8 بنوك

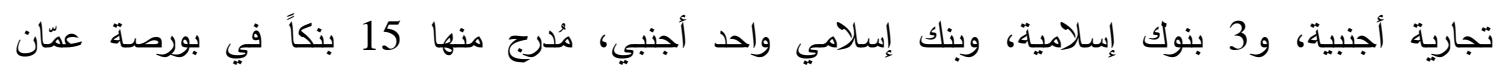
(www.cbj.gov.jo) الأردني في أنه يعتبر من أهم القطاعات التي تتصف بالنمو، ذو رأس مال وسيولة وربحية جيدة، وأن مجال

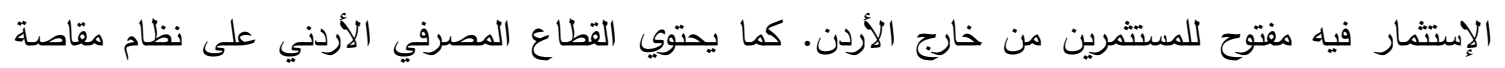

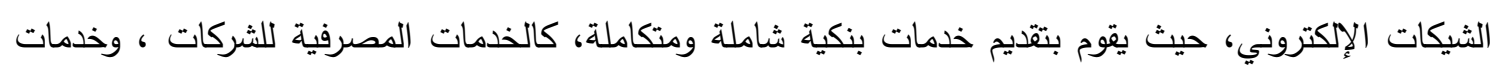
الخزينة والإستثمار ، والخدمات المصرفية الإلكترونية، والخدمات المصرفية الإسلامية.

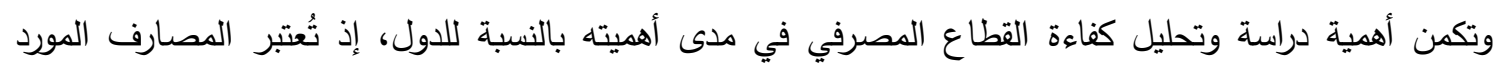

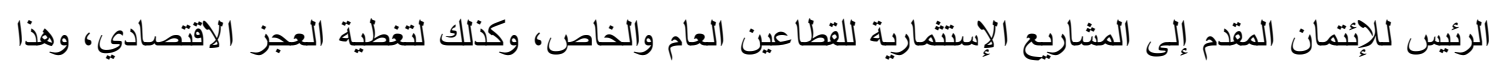
مبرر من قبل صانعي السياسة عند إهتمامهم بتصميم سياسات ملائمة من أجل نظام مصرفي أكثر كفاءة وإستقراراً،

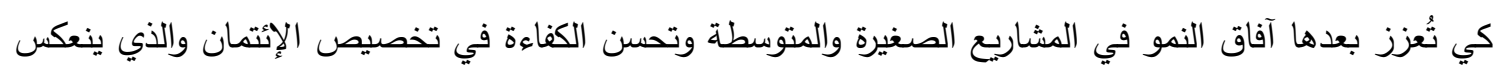

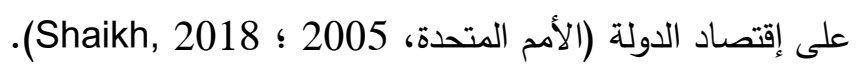


الاراسات السابقة العديد من الدراسات التي بحثت في النسب المالية وتأثيرها مؤشرات السوق المختلفة أو مختلف الأرقام القياسية. قاس شريفة وناصر(2013) كفاءة مجموعة من البنوك في الجزائر باستخدام النسب المالية من 2006- 2010. توصلت الدراسة إلى أن مؤشرات النسب المالية تُظهر مدى كفاءة البنوك والتغيرات في مستوى السيولة فيها. وقيّم عبدالجبار والجعافرة (2012) المصارف الإسلامية الاردنية بالنسب المالية لإتخاذ القرارات التمويلية ومعرفة المؤشرات المالية الأكثر أهميه بالنسبة لها. بعد توزيع إستبانه على إدارات بنك الأردن دبي الإسلامي، والبنك العربي الإسلامي الدولي، والبنك الإسلامي، وإختبار ردود أفراد العينة من خلال برنامج (SPSS).

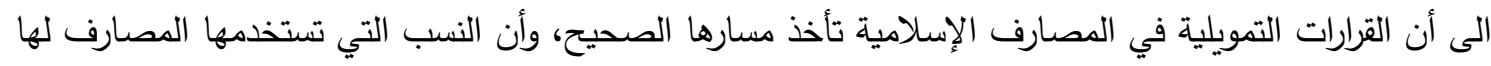

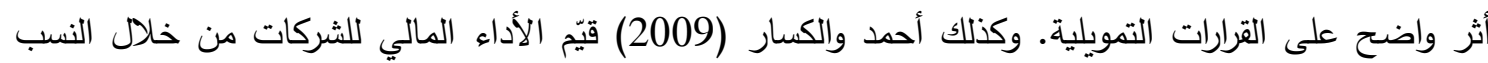
المالية، وتوصلت الدراسة إلى أن هناك 7 نسب لها تأثير مباشر على الأدئ واءكاء المالي. (Islamoglu, 2015) التركي، واختبر ما إذا كانت التغيرات في مؤشر سوق الأسهم يمكن تفسيرها في التغير بالنسب. عن طريق جمع بيانات ربعية ل13 بنكاً من السوق المصرفي التركي عام 2002 إلى عام 2013. وإيجاد معادلة تحليل الإنحدار

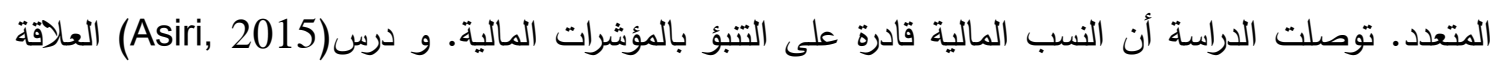
بين القيمة السوقية والنسب المالية للشركات، استخدم نسب الربحية والسيولة والكفاءة والرفع المالي لبيانات 65

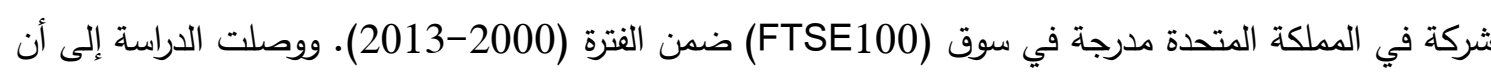
هناك علاقة إيجابية دالة احصائياً بين النسب فئ الماليه والقيمة السوقية وكذلك الأداء المالي للشركات.

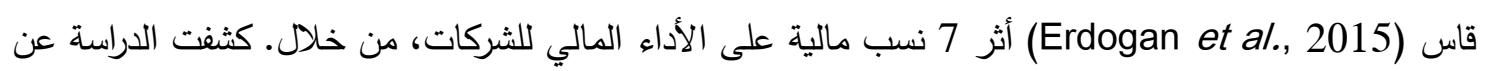
أثر إيجابي بين حجم الثركة ونسبة السيولة على الأداء المالي، بينما كان هناك تأثير سلبي على الأداء المالي

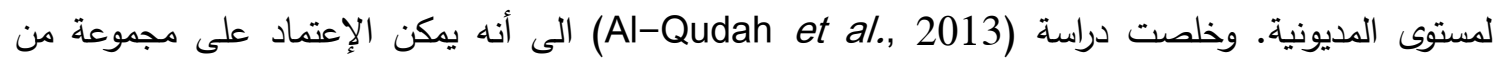
مؤشرات النسب المالية للتحقق من أداء الثركات والقطاعات المختلفة، وكذلك للتتبؤ بالعائد المستقبلي وسعر السهر.

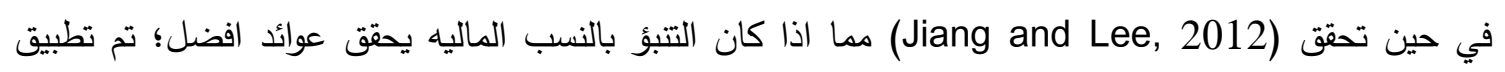
نموذج تحليلي لدورة النسب المالية من الربع الأول من عام 1926 حتى الربع الرابع من عام 2008 لمؤشر سوق

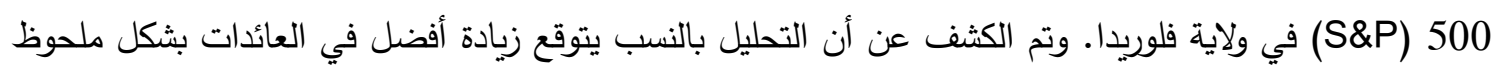
في الأجل الطويل والقصير. جاءت دراسة (Alireza et al., 2012) للتنبؤ بالأزمة المالية للشركات بمجموعة من النسب المالية كمتغير

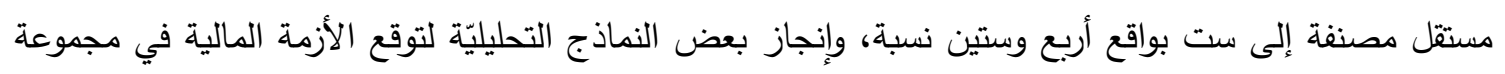

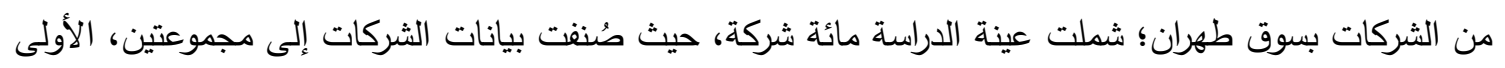
بيانات لأربع وأربعين شركه مفلسة قبل 2003، والثانية بيانات لست وخمسين شركه غير مفلسة ضئ ضمن الفترة (2003-2007). تم إجراء التحليل على خمس وتسعين شركه منهم وبينت النتائج أن للنسب الماليه أهميه كبيرة لمعرفة أداء للشركات وتوقع الإفلاس. وبنفس السياق، استكثف (Halim et al., 2011) الحالة المالية لشركات البناء في ماليزيا باستخدام النسب المالية، عبر سلسلة زمنية محددة ومقارنتها للشركة ومع شركات مختلفة؛ تم الحصول على البيانات من القوائم المالية لست شركات ماليزية كبيرة ومتوسطة الحجم ضمن ثلاث سنوات، وإستفتاء

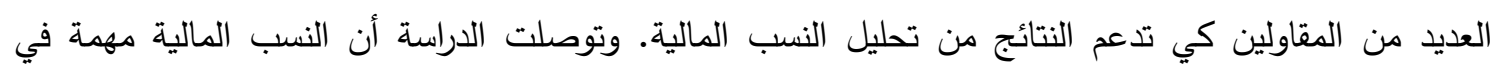
الكثف عن أداء الشركات. 
وأخيرا، دراسة (Alexakis et al., 2010) التي هدفت إلى معرفة القدرة على التتبؤ بعوائد الأسهم باستخدام المعلومات المالية، وعشر نسب مالية تم إحتسابها من خلال البيانات المالية المنشوره ل47 شركة مدرجة أسهمها

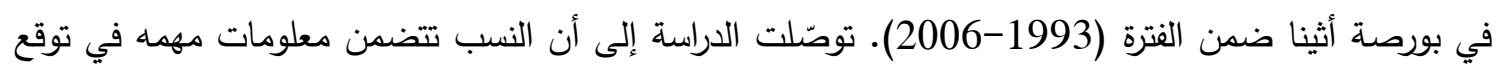
عائدات الأسهم، وأن المحافظ التي يتم إختيارها على أساس النسب تتنج أعلى من متوسط العائدات. وقد تحققت جملة من الفوائد بعد مراجعة الدراسات التي تتاولت موضوع الدراسة، تمثّلت في التعمق بمشكلة الدراسة أكثر وتحديد الأهداف، وإختيار النسب المالية الأكثر ملاءمة بالنسبة لعينة الدراسة الئختارة، وبناء منهجية الدراسة بطريقة علمية ممنهجة إستتاداً الى النماذج التي إنتهجتها معظم الأبحاث العلمية، وبعد مقارنة نتائج الدراسة بالدراسات السابقة سيثكّل صورة واضحة عن إختلاف أو توافق القدرة التنبؤية للنسب المُختارة. وجاءت هذه الدراسة بصورة مكمّله لتلك الدراسات والتي جعلت منها إسهاماً علمياً ومرجعاً جديداً ضمن الإطار العلمي المعمول بها، فقد حاولت الدراسات إختبار الأثر بين النسب المالية على مؤشرات وأداء شركات ضمن قطاعات مختلفة. منهجية الاراسة مجتمع وعينة الدراسة: يتكون مجتمع الدراسة من البنوك الأردنية المدرجة في بورصة عمّان، مصنفة حتى عام

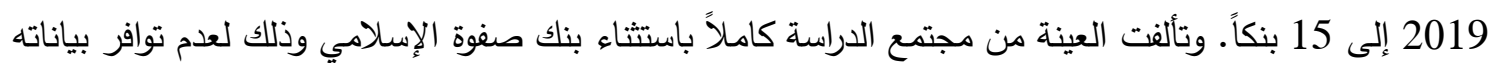
منذ بداية فترة الدراسة، حيث ستطبق على أربعة عشر بنكاً مدرجاً في بورصة عمّان، كما تم التوضيح في الجدول

الجدول رقم (1) أسماء البنوك عينة الاراسة

\begin{tabular}{|c|c|c|c|}
\hline النيك & الرق & البناك & الرق \\
\hline بنك المؤسسة العربية المصرفيه/الأردن & 8 & البنك العربي & 1 \\
\hline البنك الإستثماري & 9 & البنك الإسلامي الأردني & 2 \\
\hline بنك المال الأردني & 10 & البنك الأردني الكويتي & 3 \\
\hline بنك سوسيته جنرال - الأردن & 11 & البنك التجاري الأردني & 4 \\
\hline بنك القاهرة عمان & 12 & بنك الإسكان للتجارة والتمويل & 5 \\
\hline 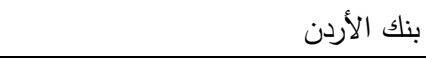 & 13 & بنك الإستثمار العربي الأردني & 6 \\
\hline البنك الأهلي الاردني & 14 & بنك الإتحاد & 7 \\
\hline
\end{tabular}

تم الإعتماد على الكتب والمقالات والأدبيات السابقة، وكذلك دليل الشركات والتقارير السنوية للشركات عينة الدراسة خلال الفترة [2005- 2014]، إضافة الى مؤشر القطاع المصرفي المحتسب في بورصة عمّان والمنشور على ولى موقعها الإلكتروني في نفس الفترة. أسلوب الاراسة

تمت تحرير البيانات باستخدام برمجية (Microsoft Excel) وتحليلها باستخدام البرنامج الإحصائي (STATA12) بين المتغيرات ومعامل الإرتباط بيرسون، وتحليل الإنحدار المتعدد بإستخدام طريقة المربعات الصغرى الإحتاءت الإعتيادية (OLS) و وإختبار (F-Ratio) 
متغيّرات الدراسة:

المتغيّر التابع ويتمثل في مؤشر القطاع المصرفي: يستند حساب مؤشر القطاع المصرفي بالترجيح في القيمة

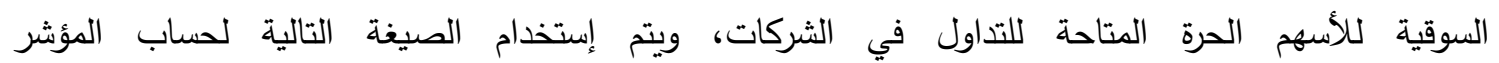

$$
I N D E X t=\frac{\sum_{i=1}^{n}(P t i * S t i * F t i)}{D t}
$$

:(www.ase.com)

حيث أن (t): الزمن، (Pti) سعر إغلاق سهم الشركة في الزمن t)، (Sti) عدد الأسهم المدرجة للشركة في الزمن t.

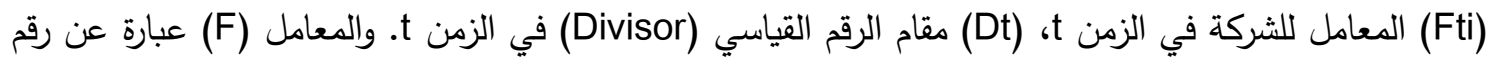
أكبر من صفر وأقل من واحد يتم إحتسابه بناءً على نسبة الأسهم الحرة في الشركة والتي تمثل الأسهم الكلية للشركة مطروحا منها أسهم أعضاء مجلس الإدارة، وكذلك يطرح منها الأسهم المملوكة للمساهمين الذين يمتلكون

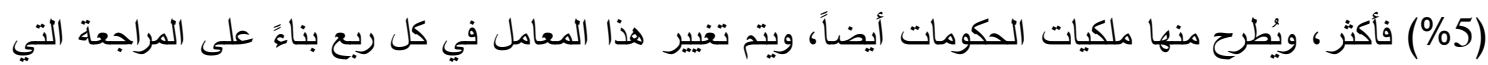

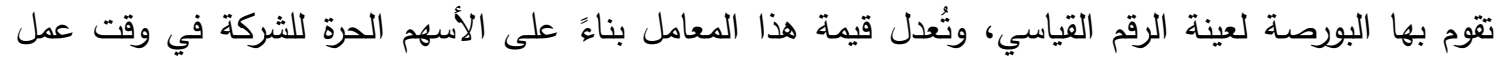
المراجعة.

المتغيّرات المستقلة متمثلة بالنسب المالية: تمّ الإعتماد على سبع نسب مالية من القوائم المالية للشركات عينة

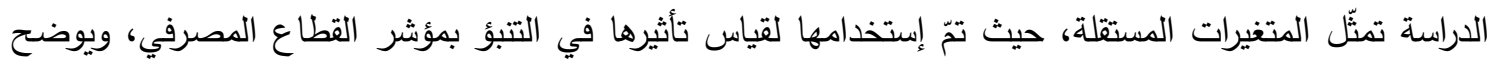

$$
\text { الجدول رقم (2) هذه النسب وطرق قياسها. }
$$

\begin{tabular}{|c|c|}
\hline طريقة القياس & النسبة \\
\hline حقوق المساهمين / مجموع الموجودات \% & نسبة الملكية \\
\hline الموجودات المتداولة / المطلوبات المتداولة (مرّة) & نسبة السيولة \\
\hline إجمالي الديون / صافي حقوق المساهمين \% & معدل المديوية \\
\hline عدد الأسهم المتداولة / عدد الأسهم الدكتتب بها \% & معدّل دوران السهم \\
\hline صافي الربح بعد الضريبة / صافي حقوق الدساهمين \% & العائد على حقوق المساهمين \\
\hline صافي الربح قبل الفوائد والضرائب / مجموع الموجودات \% & العائد على مجموع الموجودات \\
\hline القيمة السوقية للمّهُم / القيمة الدفتربة للسّهم (مرّة) & القيمة السوقية إلى القيمة الدفترية \\
\hline
\end{tabular}

الجدول رقم (2) المتغيرات المستقلة وطرق قياسها

نموذج الاراسة

يتمثل نموذج الدراسة بمعادلة الإنحدار المتعدد (Multiple Linear Regression) لتقدير العلاقة بين المتغيّر

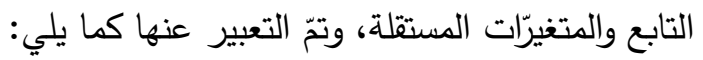
$B l_{i, t}=\alpha_{i, t}+\beta_{1} M B R_{i, t}+\beta_{2} R O A_{i, t}+\beta_{3} R O E_{i, t}+\beta_{4} S T O_{i, t}+\beta_{5} C R_{i, t}+\beta_{6} D R_{i, t}+\beta_{7} E R_{i, t}+$ $\mathcal{E}_{i, t}$

حيث أن (t) السنة، (t) الدفترية في السنة t) (ROA حقوق المساهمين في السنة t (STO,t)

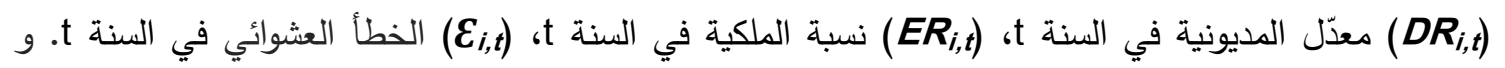


قيم تعبّر عن معاملات الإنحدار للمتغيرّات المستقلة، في حين أن ( $)$

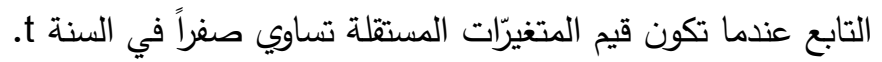
فرضيات الدراسة

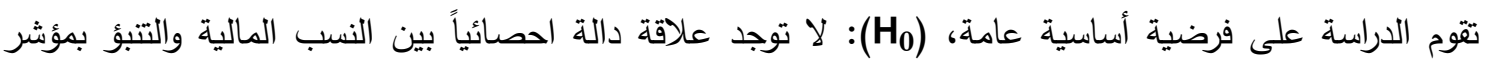

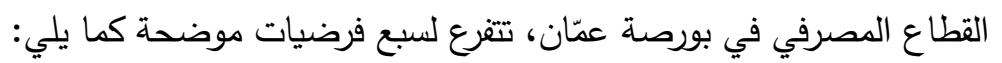

(H) (H)2) (Ho3) (H4) (المب5) (Ho6)

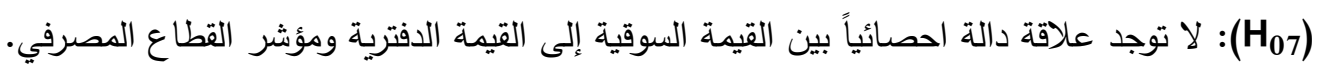
تحليل البيانات وإختبار الفرضيات تم اجراء التحليل الإحصائي لبيانات الدراسة وتطبيق الإحصاء الوصفي ، والتحقق من الإرتباطات التبادلية، وإختبار فرضيات الدراسة باستخدام طريقة المربعات الصغرى الاعتيادية (Ordinary Least Squares)، والتحقق من قيم

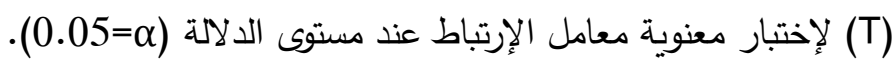

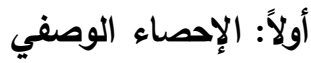
يبين الجدول (3) الإحصاء الوصفي لمتغيرات الدراسة للفترة [2005-2014]، ممثلةً في الوسط الحسابي

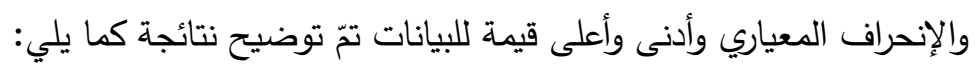

\begin{tabular}{|c|c|c|c|c|}
\hline & & & & الجدول (3): الإحصاء الوصفي لمتغيرات الدارسة \\
\hline أعلى قيمة & $\begin{array}{c}\text { أقل قيمة } \\
\text { Minimum }\end{array}$ & $\begin{array}{c}\text { الانحراف المعياري } \\
\text { Standard Deviation }\end{array}$ & $\begin{array}{l}\text { الوسط الحسابي } \\
\text { Mean }\end{array}$ & 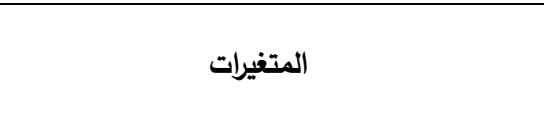 \\
\hline 6171.34 & 3407.64 & 800.57 & 4235.91 & "مؤشر القطاع المصرفي (BI)" \\
\hline 5.991 & 0.583 & 0.915 & 1.611 & "نسبة القيمة السوقية الى القيمة الدفترية MBR)" \\
\hline $70.702 \%$ & $0.030 \%$ & $28.871 \%$ & $18.819 \%$ & "معدل دوران السهم (STO)" \\
\hline 0.635 & 0.168 & 0.108 & 0.392 & "نسبة السيولة (CR)" \\
\hline $94.83 \%$ & $78.04 \%$ & $3.32 \%$ & $86.17 \%$ & "معدل المديونية (DR)" \\
\hline $39.84 \%$ & $-1.45 \%$ & $5.56 \%$ & $11.18 \%$ & "نسبة العائد على حقوق المساهمين (ROE)" \\
\hline $4.97 \%$ & $-0.17 \%$ & $0.66 \%$ & $1.50 \%$ & "نسبة العائد على مجموع الموجودات (ROA)" \\
\hline $21.96 \%$ & $1.20 \%$ & $14.77 \%$ & $14.11 \%$ & "نسبة الملكية (ER)" \\
\hline
\end{tabular}

1) يعرض الجدول (3) أن "متوسط مؤشر قطاع البنوك (BI)" بلغ (4235.91)، والإنحراف المعياري (800.57)، وكانت أقل قيمة (3407.64)، وأعلى قيمة (3171.34)، ويبين أن هناك ارتفاعاً كبيراً نسبياً في المؤشر يعود إلى التباين في التطور والإستقرار في القطاع المصرفي، حيث يعتبر القطاع المصرفي الأردني من أهم القطاعات في بورصة عمان للأورق المالية لما له دور كبير في تعظيم المؤشر العام. 
2) متوسط "القيمة السوقية إلى القيمة الدفترية (MBR)" بلغ (1.611) ، والإنحراف المعياري (0.915) ، وكانت

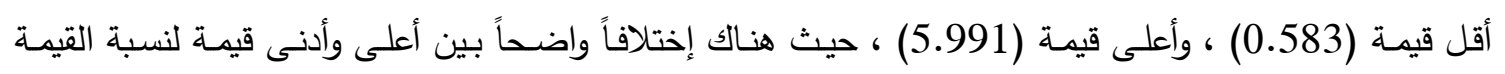

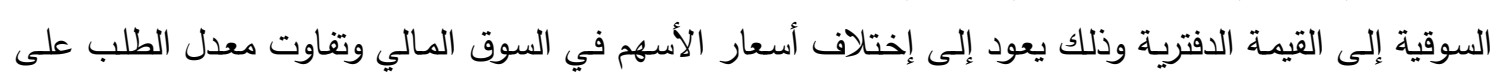
أنواع محددة من الأسهم منها ذات السيولة العالية.

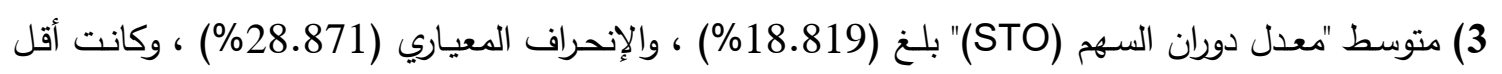

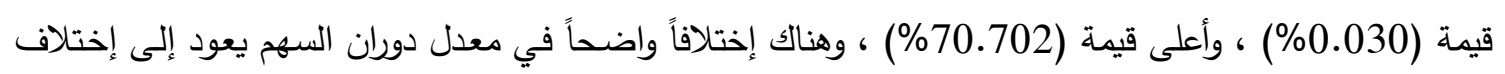

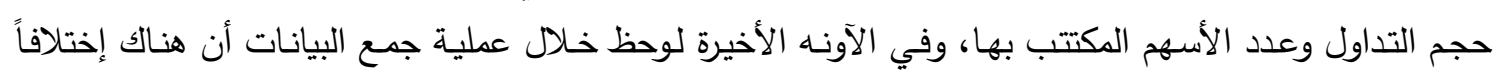

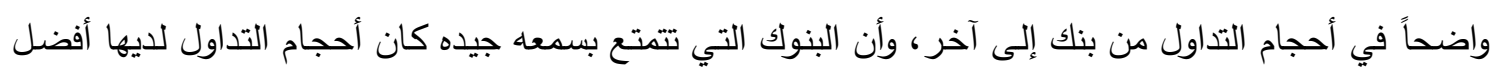
من البنوك ذات السمعة الأقل نسبياً.

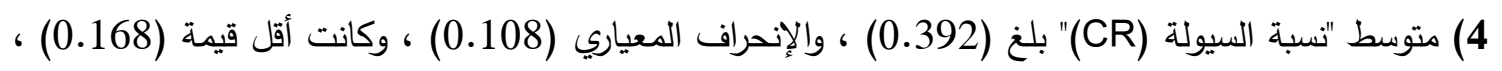

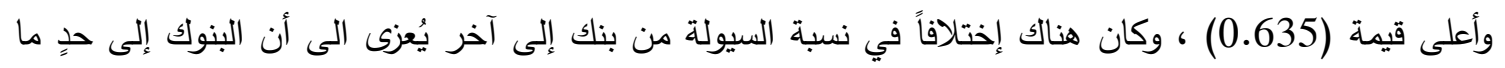

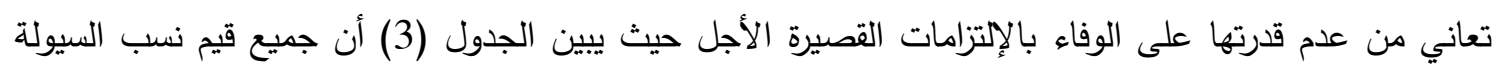
أقل من واحد.

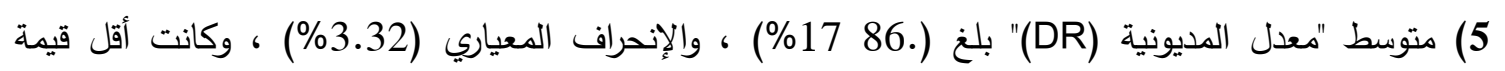
(78.04\%), وأعلى قيمة (94.83\%) ، وهذا (DR) الإختلاف في معدل المديونية أمر طبيعي لأن البنوك تعتمد بشكل شبه كامل على ودائع العملاء في تمويل إستثماراتها القائمة أو أي إستثمارات جديده.

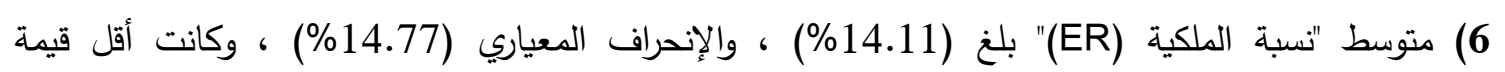
(1.20\%), وأعلى قيمة (21.96\%) ، وتختلف نسبة الملكية لدى البنوك الأردنية ويعود ذلك إلى إختلافها في طبيعة إعتمادها على أموال المالكين والإحتياطيات الأخرى.

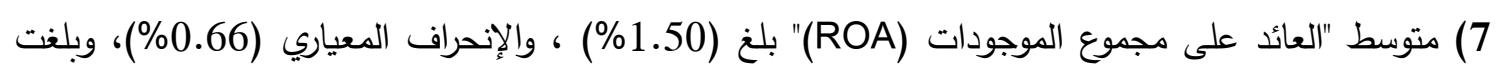

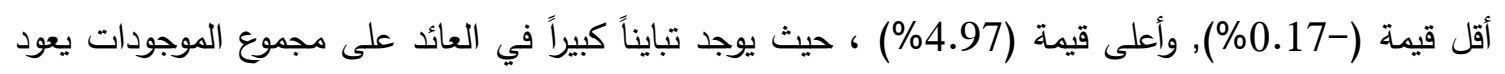
إلى التباين في عوائد البنوك، وأيضاً إلى الإختلاف في أحجام البنوك الأردنية الددرجة في بورصة عمّان فئان للأوراق المالية. 8) متوسط "العائد على حقوق المساهمين (ROE)" بلغ (11.18\%) ، والإنحراف المعياري (5.56\%)، وكانت

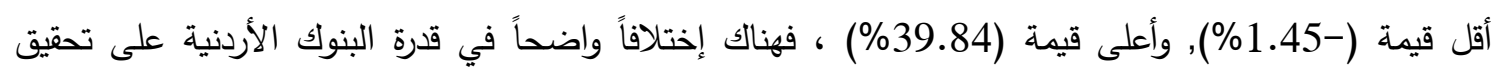

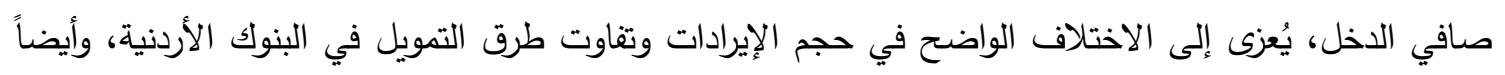

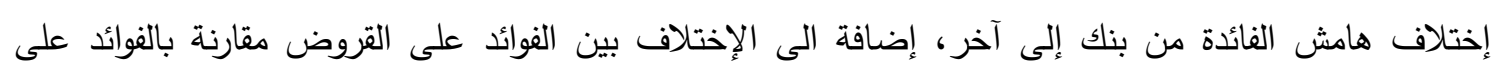
الودائع. ثانياً: إختبار مشكلة الارتباط المتعدد

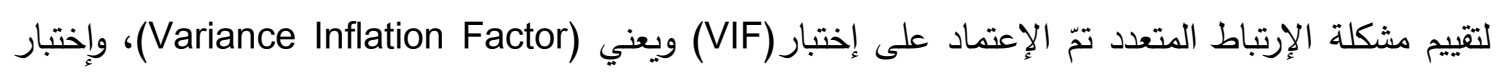
التباين (Tolerance) ويعني (1/VIF)، حيث تم مناقثة نتائجه كما يلي:

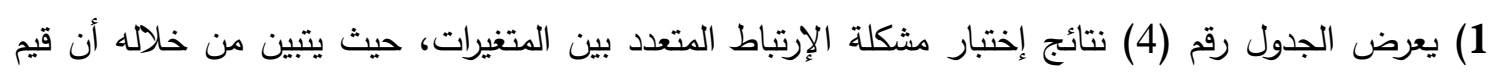

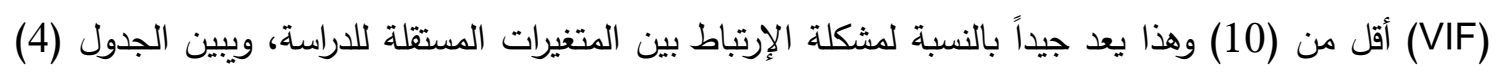

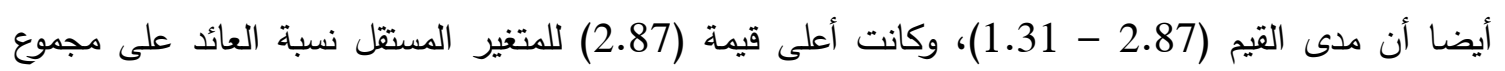


الموجودات (ROA)، وأقل قيمة (1.31) للمتغير المستقل معدل دوران السهم (STO)، كما بلغ متوسط الإنحراف المتعدد (Mean VIF) (2.04)، وهو أقل من 10، إذ يعني عدم وجود مشكلة إرتباط متعدد بين متغيرات الدراسة المستقلة (Gujarati, 2003).

\begin{tabular}{|c|c|c|}
\hline $1 / \mathrm{VIF}$ & VIF & 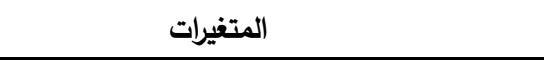 \\
\hline 0.348 & 2.87 & "نسبة العائد على مجموع الموجودات (ROA)" \\
\hline 0.356 & 2.81 & "نسبة العائد على حقوق المساهمين(ROE)" \\
\hline 0.422 & 2.37 & "معدل المديونية (DR)" \\
\hline 0.565 & 1.77 & "نسبة القيمة السوقية الى القيمة الدفترية (MBR)" \\
\hline 0.610 & 1.64 & "نسبة الملكية (ER)" \\
\hline 0.649 & 1.54 & "نسبة السيولة (CR)" \\
\hline \multirow[t]{2}{*}{0.763} & 1.31 & "معدل دوران السهم (STO)" \\
\hline & 2.04 & Mean VIF \\
\hline
\end{tabular}

2) يبيّن الجدول رقم (4) أن قيم معامل التباين (Tolerance) أقل أو يساوي واحد صحيح وهو (1/VIF) لجميع المتغيرات المستقلة، ويشير الى عدم وجود مشكلة إرتباط متعدد بين المتغيرات أيضاً (Gujarati, 2003).

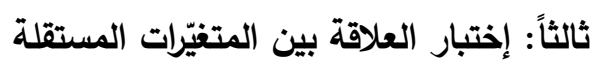
يعرض الجدول رقم (5) معامل الإرتباط "بيرسون" بين المتغيرات المستقلة لمعرفة العلاقة بينهما، إذ يعتبر إختبار

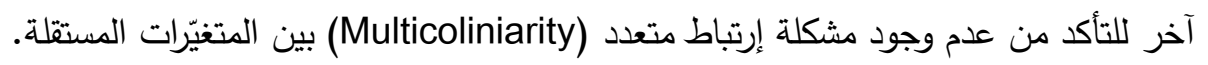

الجدول رقم (5): معامل الإرتباط "بيرسون" بين المتغيرّات المستقلة

\begin{tabular}{|c|c|c|c|c|c|c|c|}
\hline المتفيّرات & MBR & ROA & ROE & STO & CR & DR & ER \\
\hline MBR & 1 & & & & & & \\
\hline ROA & $0.194 *$ & 1 & & & & & \\
\hline ROE & $0.312^{* * *}$ & $0.116^{* * *}$ & 1 & & & & \\
\hline STO & 0.361 ** & $0.299 * * *$ & $0.172^{* * *}$ & 1 & & & \\
\hline CR & 0.248 ** & $0.301 \%$ & $0.257^{* * *}$ & $0.146 \% *$ & 1 & & \\
\hline DR & $0.197 *$ & $0.244 *$ & $0.201 * * *$ & 0.133 & 0.116 & 1 & \\
\hline ER & 0.090 & $0.091^{*}$ & 0.086 & $0.358 * *$ & $0.150 * *$ & $-0.202 * *$ & 1 \\
\hline
\end{tabular}

"**** Significant different from zero at the $1 \%$. ** Significant different from zero at the $5 \%$. * Significant different from zero at the $10 \%$."

من خلال الجدول رقم (5) يتبين أن هناك علاقة دالة إحصائياً بين بعض النسب ولكنها قليلة بحيث لا تمثّل مشكلة إرتباط متعدد، إذ بلغت أعلى نسبة (36.1\%) تمثّل العلاقة بين نسبة "القيمة السوقية إلى القيمة الدفترية (MBR) ومعدّل دوران السهم (STO)"، والنسبة التي تليها بلغت (251.2\%) تمثل العلاقة بين "نسبة العائد على حقوق المساهمين (ROE) ونسبة القيمة السوقية إلى القيمة الدفترية (MBR)" ويُعد توفر علاقات ذات دلالة إحصائية بين النسب المالية أمراً طبيعياً، لأن النسب المالية مكوّنة من أرقام مأخوذة من القوائم المالية وقد يُستخدم الرقم نفسة

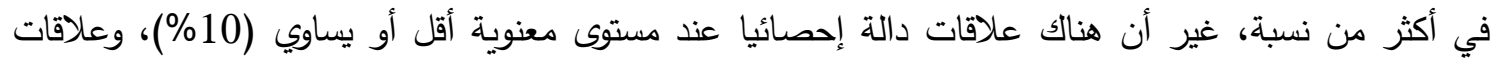




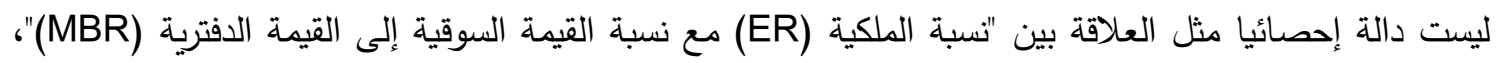
ومع "نسبة العائد على حقوق المساهمين (ROE)" كما هو موضّح في الجدول رقم (5). رابعاً: إختبار فرضيات الدراسة لوابه

تمّ الإعتماد على تحليل معادلة الإنحدار لإختبار فرضيات الدراسة باستخدام طريقة المربعات الصغرى الإعتيادية Ordinary Least Squares (OLS))

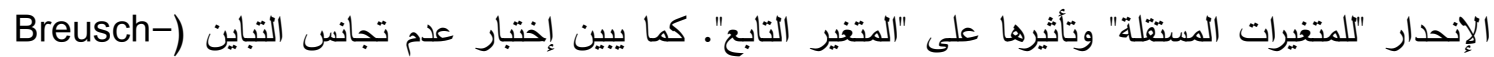
(Pagan / Test for Heteroskedasticity الإختبار أن بيانات الدراسة لم يظهر فيها مشكلة تجانس التباين، إذ كان (Chi² Statistics) الذي بلغت قيمته (9.70) غير دال احصائيا عند المستوى المعنوي المقبول لوجود مشكلة التجانس، وبهذا يتم قبول الفرضية العدمية بالنسبة لتجانس تباين البواقي. جدول رقم (6): تقدير معادلة الإنحار لنموذج الدارئ

\begin{tabular}{|c|c|c|c|}
\hline \multicolumn{4}{|c|}{$B I_{i, t}=\alpha_{i, t}+\beta_{1} M B R_{i, t}+\beta_{2} R O A_{i, t}+\beta_{a} R O E_{i, t}+\beta_{4} S T O_{i, t}+\beta_{5} C R_{i, t}+\beta_{6} D R_{i, t}+\beta_{7} E R_{i, t}+\varepsilon_{i, t}$} \\
\hline $\begin{array}{c}\text { P> |T-Test| } \\
\text { المعنوية }\end{array}$ & $\begin{array}{c}\text { T-Test } \\
\text { T إختبار }\end{array}$ & $\begin{array}{l}\text { Coefficients } \\
\text { قيمة المعامل }\end{array}$ & 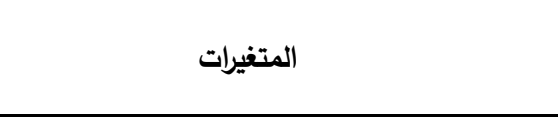 \\
\hline 0.000 & 7.250 & $0.041 * *$ & "نسبة القيمة السوقية الى القيمة الدفترية (MBR)" \\
\hline 0.000 & 4.230 & $0.067 * *$ & \multirow{2}{*}{ "نسبة العائد على مجموع الموجودات (ROA) (ROA) "نلى حقوق المساهمين (ROE)" } \\
\hline 0.020 & -2.350 & $-0.024 *$ & \\
\hline 0.000 & 4.690 & $0.103 * *$ & 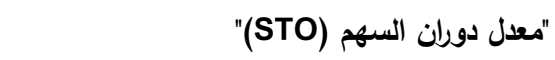 \\
\hline 0.006 & 2.810 & $0.125^{* * *}$ & "نسبة السيولة (CR)" \\
\hline 0.012 & 1.840 & $0.329 *$ & "معدل المديونية (DR)" \\
\hline 0.860 & 0.180 & 0.016 & 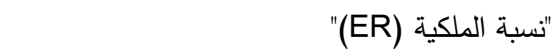 \\
\hline \multirow[t]{6}{*}{0.523} & -0.640 & -0.116 & "المعامل الثابت (Constant)" ابت \\
\hline & 0.829 & & "معامل الارتباط البسيط (Multiple R)" \\
\hline & 0.695 & & "معامل التفسير (R-squared)" \\
\hline & 0.679 & & "معامل التفسيرالمعدل(Adjusted R-squared)" \\
\hline & Prob.> |F-ratio| & Value & \multirow{2}{*}{ F-ratio } \\
\hline & 0.000 & 42.720 ** & \\
\hline
\end{tabular}

\begin{tabular}{|c|c|}
\hline \multicolumn{2}{|c|}{ إختبار عدم تجانس التباين (Breusch-Pagan / Test for Heteroskedasticity) } \\
\hline المعنوية (Prob.> |Chi²) & (Chi² Statistics) B/P قيم إختبار \\
\hline 0.362 & 9.70 \\
\hline
\end{tabular}

1) يظهر الجدول رقم (6) أن قيمة المعامل (Coefficient) لنسبة الملكية (ER) بلغت (0.016)، وبلغت قيمة إختبار T-test) T) (0.180)، مما يعني وجود أثر إيجابي غير دال احصائيا لنسبة الملكية على تفسير المؤشر

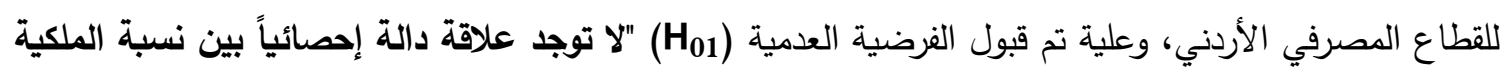
ومؤشر القطاع المصرفي". 
2) قيمة المعامل (Coefficient) لنسبة السيولة (CR) بلغت (0.125)، ودال إحصائياً عند مستوى معنوي أقل أو يساوي 1\%، وبلغت قيمة إختبار T-test) T) (2.81)، مما يعني وجود أثر إيجابي دال احصائياً لنسبة السيولة معندي مع مؤشر القطاع المصرفي، ويُظهر ذلك أنه "كلما زادت نسبة السيولة في البنوك الأردنية يتحسّن مؤشر القطاع

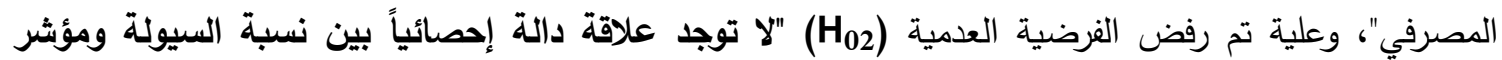

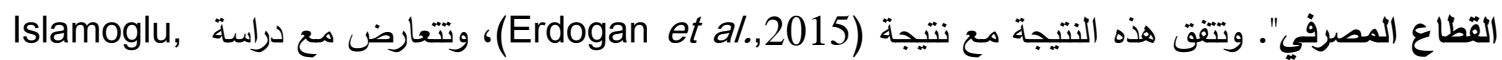

3) قيمة المعامل (Coefficient) لمعدل المديونية (DR) بلغت (0.329) ودال إحصائياً بمستوى معنوي أقل أو يساوي 5\%، وبلغت قيمة إختبار T-test) T) (1.840)، مما يعني وجود أثر إيجابي دال احصائياً على تفسير

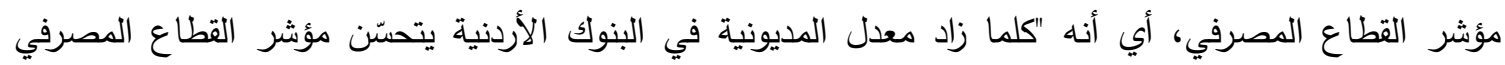
الأردني"، وعلية تم رفض الفرضية العدمية (Ho3 (H) "لا توجد علاقة دالة إحصائياً بين معدل المديونية ومؤشر

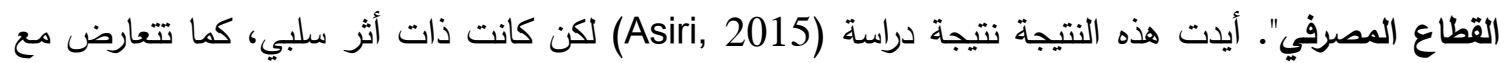
دراسة (Kumbirai \& Webb,2010) بعدم وجود علاقة.

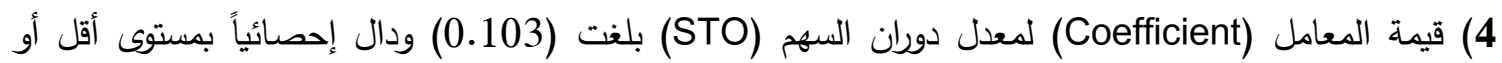
يساوي 1\%، وبلغت قيمة إختبار T-test) T) (4.690)، مما يعني وجود أثر إيجابي دال إحصائياً لمعدل دوران السهم على تفسير المؤشر للقطاع المصرفي الأردني، وبمعنى آخر "كلما زاد معدل دوران السهم في البنوك الأردنية تحسّن مؤشر القطاع المصرفي الأردني"، وعلية تم رفض الفرضية العدمية (Ho4 (H) "لا توجد علاقة دالة إحصائياً بين معدل دوران السهم والتنبؤ بمؤشر القطاع المصرفي".

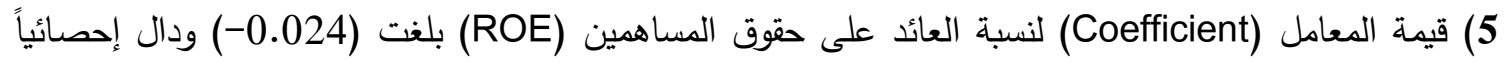
بمستوى معنوي أقل أو يساوي 5\%، وبلغت قيمة إختبار T-test) T) (2.35-)، مما يعني وجود أثر سلبي دال إحصائياً لنسبة العائد على حقوق المساهمين على تفسير المؤشر للبنوك الأردنية، ويدل ذلك "على وجود علاقة عكسية لنسبة العائد على حقوق المساهين في البنوك الأردنية مع مؤشر القطاع المصرفي الأردني"، وعلية تم رفض الفرضية العدمية (Ho5) "لا توجد علاقة دالة إحصائياً بين نسبة العائد على حقوق المساهمين ومؤشر مؤنر القطاع المصرفي". 6) قيمة المعامل (Coefficient) لنسبة العائد على مجموع الموجودات (ROA) بلغت (0.067) ودال إحصائياً عند مستوى معنوي أقل أو يساوي 1\%، وبلغت قيمة إختبار T-test) T) (4.23)، مما يعني وجود أثر إيجابي دال إحصائياً لنسبة العائد على مجموع الموجودات على تفسير مؤشر القطاع المصرفي، ويدل ذلك على وجود علاقة طردية لنسبة العائد على مجموع الموجودات مع المؤشر ، أي أنه كلما زادت هذه النسبة كلما كان ذلك لكوات مؤشراً

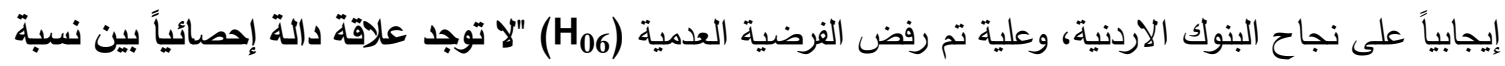
العائد على مجموع الموجودات ومؤشر القطاع". 7) قيمة المعامل (Coefficient) لنسبة القيمة السوقية إلى القيمة الدفترية (MBR) بلغت (0.041) ودال إحصائياً عند مستوى معنوي أقل أو يساوي 1\%، وبلغت قيمة إختبار T-test) T) (7.25)، مما يعني وجود أثر إيجابي دال إحصائياً لنسبة القيمة السوقية إلى القيمة الدفترية على تفسير المؤشر للبنوك الأردنية, ويدل ذلك أنه كلما زادت

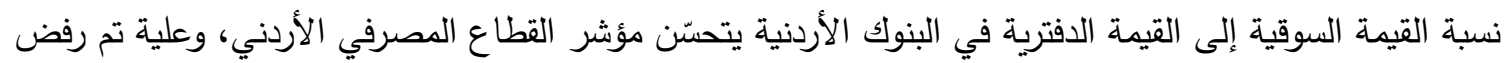
الفرضية العدمية (Ho7) "لا توجد علاقة دالة إحصائياً بين نسبة القيمة السوقية إلى القيمة الدفترية ومؤشر الإنية القطاع المصرفي". أيدت هذه النتيجة نتيجة دراسة (Jiang, 2012) ودراسة (Al-Qudah et al.,2013). 


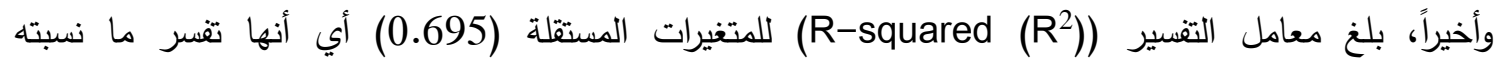

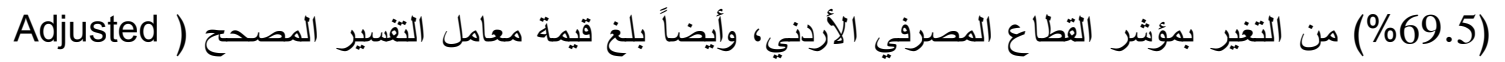
(R-squared أن قيمتها بلغت (42.72) ودالة إحصائياً عند مستوى معنوي أصغر أو يساوي (1)، والتية (1). وعلية وبعد مناقشة الفرضيات الفرعية، تم رفض الفرضية العدمية الرئيسة (Ho (التي تتص على أنه "لا توجد علاقة دالة إحصائياً بين النسب المالية والتتبؤ بمؤشر القطاع المصرفي في بورصة الترة عمّان".

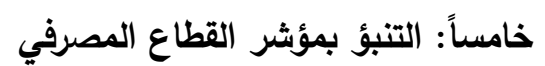
يوضّح الجدول رقم (7) العلاقة بين المتغيرّات، بحيث يبين قيم معاملات (Coefficients) النسب المالية في معادلة الإنحدار المتعدد والتي من خلالها يمكن التتبؤ بمؤشر القطاع المصرفي، ويبين الجدول رقم (7) معامل التفسير (R-squared (R²), الذي من خلالة يبين قدرة تفسير النموذج المكون من النسب المالية في التغير بمؤشر القطاع المصرفي، وكذلك ملخص عن وجود أثر بين النسب المختارة على مؤشر القطاع المصرفي، إضافة إلى خلاصة قبول ورفض فرضيات الدراسة المستتدة إلى كل نسبة. الجدول رقم (7): العلاقة بين المتفيّرات

\begin{tabular}{|c|c|c|c|c|}
\hline $\mathbf{R}^{2}$ & الفرضية & العلاقة & المعامل & النسبة \\
\hline \multirow{7}{*}{0.695} & قبول & لا يوجد علاقة & 0.016 & "نسبة الملكية (ER)" \\
\hline & 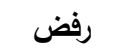 & علاقة إيجابية & 0.125 & "نسبة السيولة (CR)" \\
\hline & 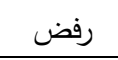 & علاقة إيجابية & 0.329 & "معدل المديونية (DR) \\
\hline & 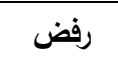 & علاقة إيجابية & 0.103 & "معدل دوران السهم (STO)" \\
\hline & 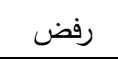 & علاقة سلبية & -0.024 & "نسبة العائد على حقوق المساهمين (ROE)" \\
\hline & رفض & علاقة إيجابية & 0.067 & "نسبة العائد على مجموع الموجودات (ROA)" \\
\hline & رفض & علاقة إيجابية & 0.041 & "نسبة القيمة السوقية الى القيمة الدفترية (MBR)" \\
\hline
\end{tabular}

يوضّح الجدول رقم (7) أن كل من نسبة السيولة ومعدل المديونية ومعدل دوران السهم والعائد على مجموع الموجودات والقيمة السوقية الى القيمة الدفترية ترتبط بعلاقة ايجابية مع مؤشر القطاع المصرفي في بورصة عمان، وعليه يمكن أن نتتبأ في بالمؤشر بشكل ايجابي. اضافة الى ذلك، يبين الجدول (7) أن نسبة العائد على حقوق فئه

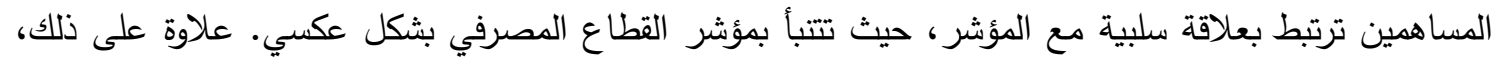
تبين أنه لا يوجد علاقة بين نسبة السيولة ومؤشر القطاع المصرفي في بورصة عمان، وبهذا لا تتنبأ بالمؤشر .

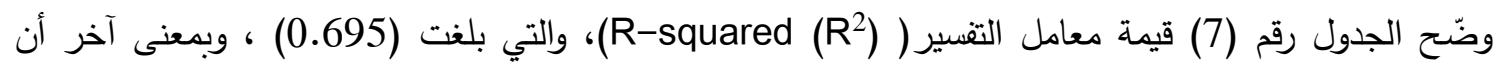
(69.5\%) من التغير في مؤشر القطاع المصرفي في بورصة عمّان يعود إلى التغيرات في النسب المالية التي

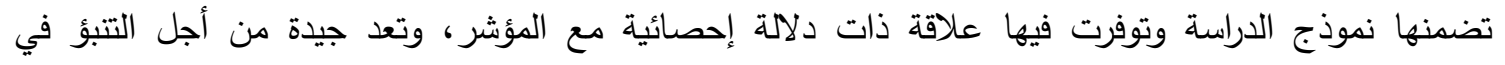
المؤشر ، لذلك يمكن التتبؤ بمؤشر القطاع المصرفي في بورصة عمّان من خلال هذا النموذج.

الخلاصة

مع تطور الأسواق المالية في الآونة الأخيرة، اصبح هناك ضرورة ملحة لمعرفة العلاقة بين النسب المالية

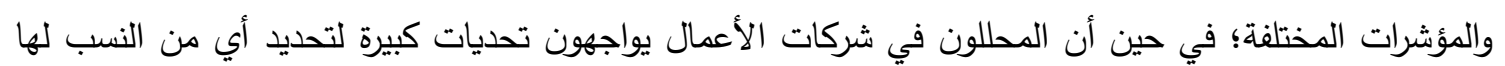
العلاقة الهامه والتأثير الأكبر والقدرة على التتبؤ بأداء مؤشرات الأسواق. هدفت الداستة الأدات الحالية إلى إختبار قدرة 
نسبة الملكية، والسيولة، ومعدل المديونية، ومعدل دوران السهم، والعائد على حقوق المساهمين، والعائد على مجموع

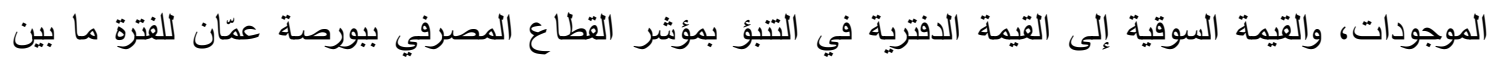

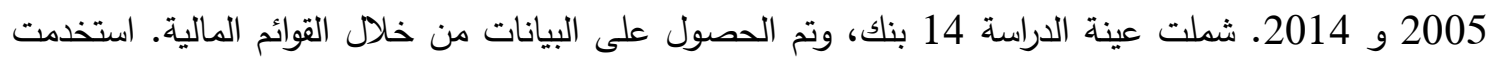

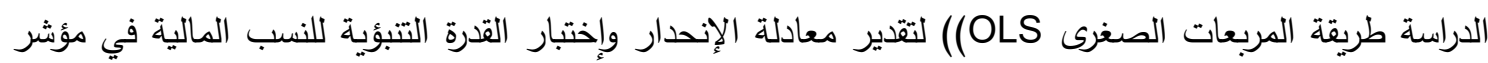
القطاع المصرفي. أظهرت النتائج أن النسب المالية قادرة على التتبؤ بمؤشر القطاع المصرفي، حيث يمكن لنسبة

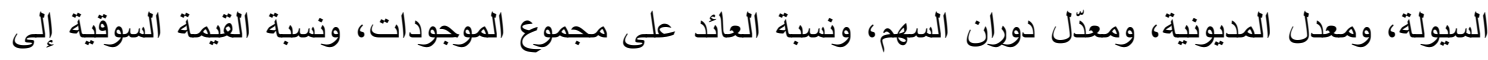
القيمة الدفترية التتبؤ بمؤشر القطاع المصرفي في بورصة عمّان بشكل ايجابي. كما يمكن لنسبة العائد على حقوق المساهمين التتبؤ مؤشر القطاع المصرفي في بورصة عمّان بثكل عكسي. في حين انه لا يمكن لنسبة الملكية

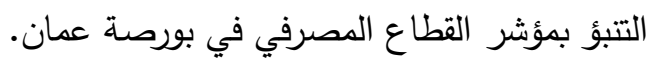
إستطاع نموذج الدراسة المكوّن من النسب المالية التي كانت على علاقة ذات دلالة إحصائية مع المؤشر والمتمثلة

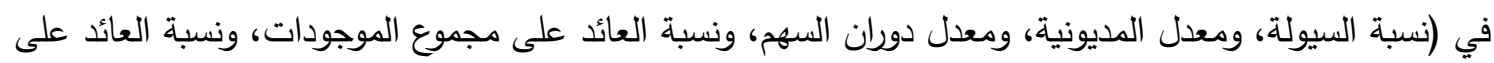

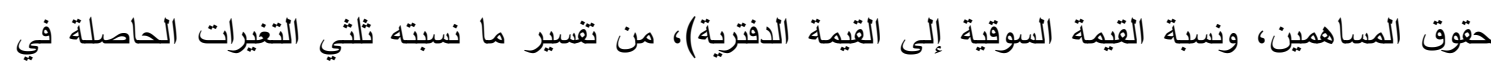

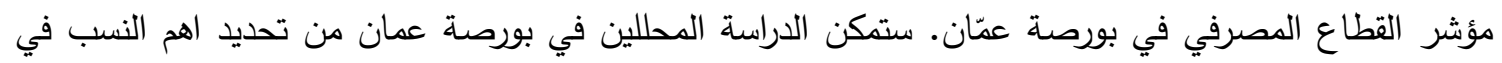
الأسواق الماليه وكذلك تعطي فرصة للمستثمرين من اختيار الفرص الاستثمارية الأنسب في السوق.

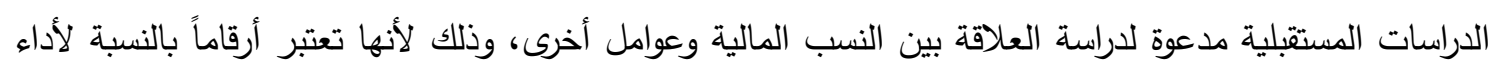

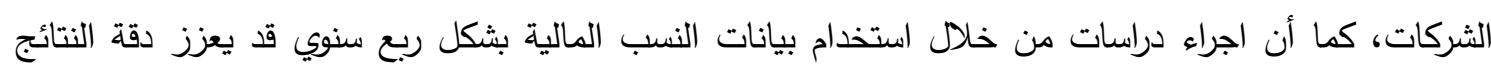
لأنها تستتد إلى بيانات ربع سنوية تقود إلى نتائج أكثر دقة عند قياس قدراء دات النسات النسب المالية على التتبؤ بالمؤشرات

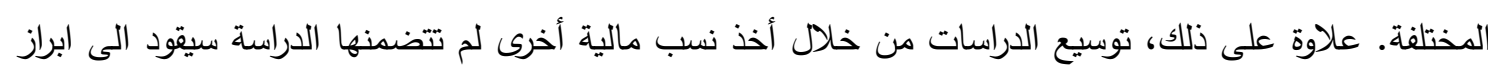
صورة مكتملة عن قدرة النسب جميعها في التتبؤ بمؤشر القطاعات المختلفة.

المراجع

أبو شمالة، نصر والدهدار ، مروان (2007م). " الإدارة المالية ". مكتبة المعرفة، غزة، فلسطين. أحمد، محمود والكسار ، طلال (2009م)." إستخدام مؤشرات النسب المالية في تقويم الإداء المالي والتتبؤ بالأزمات

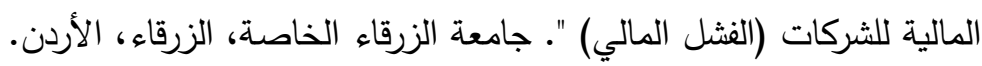
اكامولا، هوشيار (2003)." الاستثمارات والأسواق المالية ". عمان، الأردن، دار الصفاء للنشر والتوزيع.

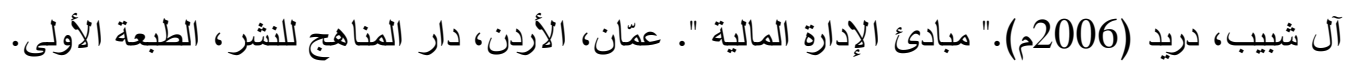

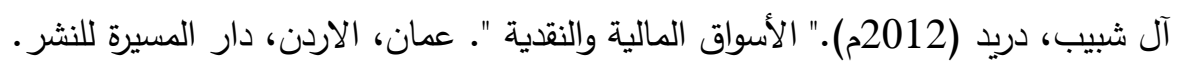

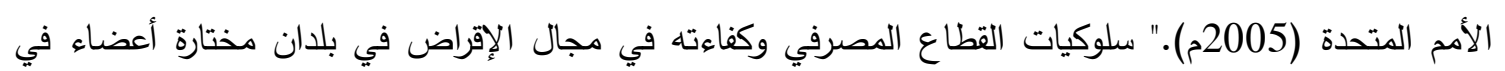
الإسكوا ". مطبوعات الأمم المتحدة, نيويورك، العدد3.

حنفي، عبد الغفار (2004م)." أساسيات التحليل المالي ودراسات الجدوى ". الإسكندرية، مصر الدار الجامعية للنشر

الحيالي، وليد (2004م)." الإتجاهات المعاصرة في التحليل المالي ". عمان، الأردن، دار الورّاق للنشر .

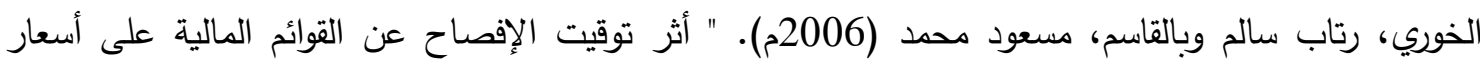

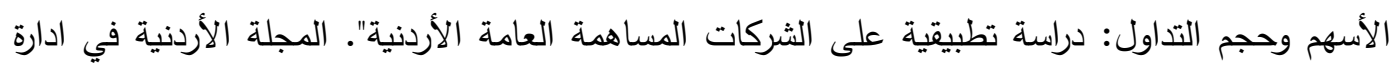

الأعمال، المجلد 2، العدد2. 
الدوري، مؤيد وزناد، نور الدين (2003م)." التحليل المالي باستخدام الحاسوب". دار وائل للنشر ، عمان، الأردن. الزرري، عبد النافع وفرح، غازي (2001م)." الأسواق المالية ". دار وائل للنشر ، عمان، عان، الأردن. السعايدة، فيصل وفريد، نظال (2004م)." الملخص الوجيز للإدارة والتحليل المالي ". عمّان، الأردن، مكتبة الإنة المجتمع العربي للنشر والتوزيع.

السهلي، محمد (2011م)." التحليل المالي (نظرة محاسبية)". الرياض، السعودية، الجمعية السعودية للمحاسبة، الطبعة الثانية.

الثديفات، خلدون (2001م)." إدارة وتحليل مالي ". الأردن، عمان، دار وائل للنشر والطباعة.

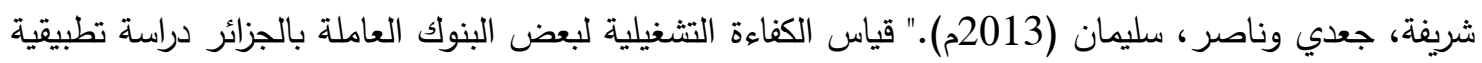
خلال الفترة (2000-2010) ". مجلة الباحث، العدد12, جامعة قاصدي مرباح ورقلة، الجزائر . الثلبي، طارق والثلبي، محمد (2000م). " الأسواق المالية ". عمان، الاردن، دار وائل للنشر.

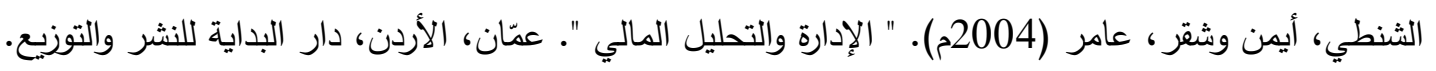
عبدالجبار، أسامة والجعافرة، أحمد (2012م). " مدى استخدام النسب المالية في اتخاذ القرارات التمويلية في

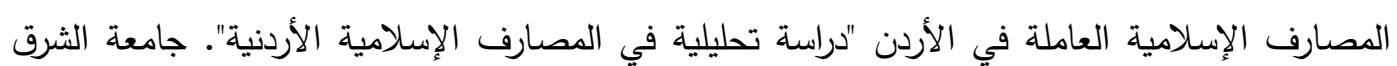
الأوسط، عمّان، الأردن.

عقل، مفلح (2000م)." مقدمة في الإدارة المالية والتحليل المالي ". عمان، الأردن، دار المستقبل للنشر .

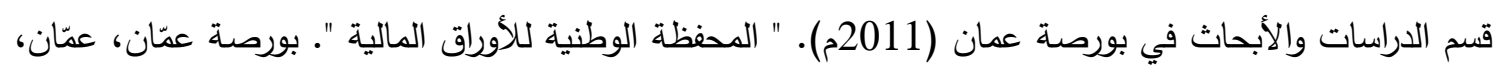
الأردن.

كراجة، عبدالحليم وربابعة، علي والسكران، ياسر ومطر ، موسى (2002م)." الإدارة والتحليل المالي ". عمّان، الأردن، دار الصفاء للنشر ، الطبعة الثانية.

مطر ، محمد (2003م)." الاتجاهات الحديثة في التحليل المالي والائتماني ". عمان، الأردن، دار وائل للنشر . النجار ، فريد (2002م)." القوائم المالية والتحليل المالي ". مصر ، المكتبة المصرية.

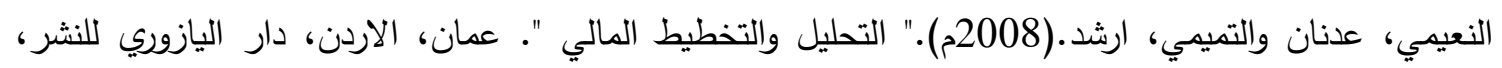
الطبعة العربية. هندي، منير إبراهيم (2002م)." ادارة الأسواق والمنشأة المالية ". منشأة المعارف، الإسكندرية، مصر .

\section{References}

Aal-Shabib, D. (2006). Principles of Financial Management. Amman, Jordan, Dar AlManaheg Publishing, First Edition. (in Arabic)

Aal-Shabib, D. (2012). Financial and Monetary Markets. Amman, Jordan, Dar AlMaisarah Publishing (in Arabic)

Abdul-Jabbar, O. and Jafra, A. (2012). The Use of Financial Ratios in Decision Making in Islamic Banks Operating in Jordan- An Analytical Study in Jordanian Islamic Banks , Middle East University, Amman, Jordan. (in Arabic)

Abu Shammala, N. and Al-Dahdhar, M. (2007). Financial management. Knowledge Library, Gaza, Palestine (in Arabic) 
Ahmed, M., Al-Kassar, T. (2009). Using Financial Ratios to Evaluate Financial Performance and Predict Corporate Financial Crises (Financial Failure). Zarqa Private University, Zarqa, Jordan. (in Arabic)

Akwamola, H. (2003). Investments and Financial Markets. Amman, Jordan, Dar Al-Safa Publishing and Distribution. (in Arabic)

Alareeni, B. (2018). Does corporate governance influence earnings management in listed companies in Bahrain Bourse?, Journal of Asia Business Studies, 12(4), 551-570. https://doi.org/10.1108/JABS-06-2017-0082

Alareeni, B. (2019). A Review of Auditors' GCOs, Statistical Prediction Models and Artificial Intelligence Technology, International Journal of Business Ethics and Governance, 2(1), pp. 19-31. https://doi.org/10.51325/ijbeg.v2i1.30

Alareeni, B., \& Branson, J. (2013). Predicting Listed Companies' Failure in Jordan Using Altman Models: A Case Study. International Journal of Business and Management, 8(1), 113-126. https://doi.org/10.5539/ijbm.v8n1p113

Al-Douri, M. and Zenad, N. (2003). Computerized Financial Analysis. Dar Wael Publishing, Amman, Jordan. (in Arabic)

Alexakis, C., Patra, T., \& Poshakwale, S. (2010). Predictability of stock returns using financial statement information: evidence on semi-strong efficiency of emerging Greek stock market. Applied Financial Economics, 20(16), 1321-1326. https://doi.org/10.1080/09603107.2010.482517

Ali, Q., Maamor, S., Yaacob, H. and Tariq Gill, M. U. (2018). Impact of Macroeconomic Variables on Islamic Banks Profitability, International Journal of Business Ethics and Governance, 1(2), pp. 20-35. https://doi.org/10.51325/ijbeg.v1i2.14

Alireza, F., Parviz, M., \& Mina, S. (2012). Evaluation of the financial ratio capability to predict the financial crisis of companies. IUP Journal of Behavioral Finance, 9(1), 57.

Al-Najjar, F. (2002). Financial Statements and Financial Analysis. Egypt, the Egyptian Library. (in Arabic)

Al-Nuaimi, A. and Al-Tamimi, A. (2008). Analysis and Financial Planning. Amman, Jordan, Dar Al Yazuri Publishing, Arabic edition. (in Arabic)

Al-Qudah, A. A., Alsharari, N. M., Al-Rjoub, A. M., \& Haddad, W. (2013). Importance of Financial Analysis for Published Financial Information to Predict the Stocks Behavior (Case study-ASE-Industrial Sector-Jordan). European Journal of Business and Management, 5(26), 96-102.

Al-Sa'aida, F. and Farid, N. (2004). Brief summary of management and financial analysis. Amman, Jordan, Arab Society Library for Publishing and Distribution. (in Arabic)

Amman Stock Exchange: www.ase.com

Aqel, M. (2000). Introduction to Financial Management and Financial Analysis. Amman, Jordan, Dar Almustaqbal Publishing. (in Arabic)

Asiri, B. K. (2015). How investors perceive financial ratios at different growth opportunities and financial leverages. Journal of Business Studies Quarterly, 6(3), 1.

Bragg, S. M. (2012). Business ratios and formulas: a comprehensive guide (Vol. 577). John Wiley \& Sons. https://doi.org/10.1002/9781119203155

Central Bank of Jordan: www.cbj.gov.jo

Erdogan, E. O., Erdogan, M., \& Ömürbek, V. (2015). Evaluating the effects of various financial ratios on company financial performance: Application in Borsa Istanbul, Business and Economics Research Journal, 6(1), 35-42. 
Gujarati, D. N., \& Porter, D. C. (1999). Essentials of econometrics (Vol. 2). Singapore: Irwin/McGraw-Hill.

Halim, S. A., Jaafar, M., \& Osman, O. (2011). Assessment of the financial health of malaysian construction firms using financial ratio analysis. International journal of academic research, 3(1).

Hanafi, A.G. (2004). Fundamentals of Financial Analysis and Feasibility Studies. Aleskandaria, Egypt, Dar Al-University Publishing. (in Arabic)

Harringtonn, Diana R (1993). Corporate Financial Analysis, 4 edition, USA, Boston, Homewood.

Hayali, W. (2004). Contemporary Trends in Financial Analysis. Amman, Jordan, Dar Al-Warraq Publishing. (in Arabic)

Hindi, M. I. (2002). Managing Markets and Financial Facility, El Maaref Establishment, Alexandria, Egypt. (in Arabic)

Islamoglu, M. (2015). Predictive Power of Financial Ratios with Regard to the Turkish Banking Industry an Empirical Study on the Stock Market Index. Asian Economic and Financial Review, 5(2), 249-263. https://doi.org/10.18488/journal.aefr/2015.5.2/102.2.249.263

Jiang, X., \& Lee, B. S. (2012). Do decomposed financial ratios predict stock returns and fundamentals better? Financial Review, 47(3), 531-564. https://doi.org/10.1111/j.1540-6288.2012.00339.x

Karajah, A., Rababah, A., Al-Sakran, Y., and Mattar, M. (2002). Management and Financial Analysis. Amman, Jordan, Dar Al Safa Publishing, second edition. (in Arabic)

Khoury, R.S., and Baqasim, M.M. (2006). Effect of Timing of Disclosure of Financial Statements on Stock Prices and Volume: An Empirical Study on Jordanian Public Shareholding Companies. Jordanian Journal of Business Administration, 2(2). (in Arabic)

Malgwi, A. A., \& Dahiru, H. (2014). Balanced Scorecard financial measurement of organizational performance: A review. Journal of Economics and Finance, 4(6), 2321-5933. https://doi.org/10.9790/5933-0460110

Matar, M. (2003). Recent trends in financial and credit analysis. Amman, Jordan, Dar Wael Publishing. (in Arabic)

Merza Radhi, D. S. and Sarea, A. (2019). Evaluating Financial Performance of Saudi Listed Firms: Using Statistical Failure Prediction Models, International Journal of Business Ethics and Governance, 2(1), pp. 1-18. https://doi.org/10.51325/ijbeg.v2i1.20

Pilbeam, Keith, (2007). Finance \& Financial Markets" 10 edition", England, Bristol.

Robinson, T. R. (2020). International financial statement analysis. John Wiley \& Sons.

Sahli, M. (2011). Financial Analysis (Accounting Perspective). Riyadh, Saudi Arabia, Saudi Accounting Association, Second Edition. (in Arabic)

Shalabi, T. and shalabi, M. (2000). Financial Markets. Amman, Jordan, Dar Wael Publishing. (in Arabic)

Shanti, A. and Shaker, A. (2004). Management and Financial Analysis. Amman, Jordan, Dar Al-Thaithia for Publishing and Distribution (in Arabic)

Sharifa, J. and Nasser, S. (2013). Measuring the Operational Efficiency of Some Banks Operating in Algeria, Applied Study during the Period (2000-2010), Journal of the researcher, No. 12, University of Qasdi Marbah and Argla, Algeria. (in Arabic)

Shudifat, Kh. (2001). Financial Management and Analysis. Jordan, Amman, Dar Wael publishing and printing. (in Arabic)

Subramanyam, K. R. (2014). Financial statement analysis. McGraw Hill Education. 
United Nations (2005). Banking Sector Conduct and Efficiency in Lending in Selected ESCWA Member Countries, United Nations publication, New York, No. 3. (in Arabic)

Zari, A.N.and Farah, G. (2001). Financial Markets. Dar Wael Publishing, Amman, Jordan. (in Arabic) 